\title{
Characterisation of short-term extreme methane fluxes related to non-turbulent mixing above an Arctic permafrost ecosystem
}

\author{
Carsten Schaller $^{1,2, a}$, Fanny Kittler ${ }^{2}$, Thomas Foken ${ }^{1,3}$, and Mathias Göckede ${ }^{2}$ \\ ${ }^{1}$ Department of Micrometeorology, University of Bayreuth, 95440 Bayreuth, Germany \\ ${ }^{2}$ Max-Planck-Institute for Biogeochemistry, 07745 Jena, Germany \\ ${ }^{3}$ University of Bayreuth, Bayreuth Center of Ecology and Environmental Research (BayCEER), 95440 Bayreuth, Germany \\ a now at: University of Münster, Institute of Landscape Ecology, Climatology Research Group, \\ Heisenbergstr. 2, 48149 Münster, Germany
}

Correspondence: Mathias Göckede (mathias.goeckede@bgc-jena.mpg.de)

Received: 14 March 2018 - Discussion started: 12 June 2018

Revised: 18 February 2019 - Accepted: 5 March 2019 - Published: 1 April 2019

\begin{abstract}
Methane $\left(\mathrm{CH}_{4}\right)$ emissions from biogenic sources, such as Arctic permafrost wetlands, are associated with large uncertainties because of the high variability of fluxes in both space and time. This variability poses a challenge to monitoring $\mathrm{CH}_{4}$ fluxes with the eddy covariance (EC) technique, because this approach requires stationary signals from spatially homogeneous sources. Episodic outbursts of $\mathrm{CH}_{4}$ emissions, i.e. triggered by spontaneous outgassing of bubbles or venting of methane-rich air from lower levels due to shifts in atmospheric conditions, are particularly challenging to quantify. Such events typically last for only a few minutes, which is much shorter than the common averaging interval for EC (30 min). The steady-state assumption is jeopardised, which potentially leads to a non-negligible bias in the $\mathrm{CH}_{4}$ flux. Based on data from Chersky, NE Siberia, we tested and evaluated a flux calculation method based on wavelet analysis, which, in contrast to regular EC data processing, does not require steady-state conditions and is allowed to obtain fluxes over averaging periods as short as $1 \mathrm{~min}$. Statistics on meteorological conditions before, during, and after the detected events revealed that it is atmospheric mixing that triggered such events rather than $\mathrm{CH}_{4}$ emission from the soil. By investigating individual events in more detail, we identified a potential influence of various mesoscale processes like gravity waves, low-level jets, weather fronts passing the site, and cold-air advection from a nearby mountain ridge as the dominating processes. The occurrence of extreme $\mathrm{CH}_{4}$ flux events over the summer season followed a seasonal course with a maximum in early August, which is strongly correlated with
\end{abstract}

the maximum soil temperature. Overall, our findings demonstrate that wavelet analysis is a powerful method for resolving highly variable flux events on the order of minutes, and can therefore support the evaluation of EC flux data quality under non-steady-state conditions.

\section{Introduction}

Methane $\left(\mathrm{CH}_{4}\right)$ is one of the most important greenhouse gases (Saunois et al., 2016b), but unexpected changes in atmospheric $\mathrm{CH}_{4}$ budgets over the past decade emphasise that many aspects regarding the role of this gas in the global climate system remain unexplained to date (e.g. Saunois et al., 2016a; Nisbet et al., 2016; Schwietzke et al., 2016; Schaefer et al., 2016). Atmospheric $\mathrm{CH}_{4}$ increased in concentration from $722 \mathrm{ppb}$ in the year 1850 , i.e. before industrialisation started, to $1810 \mathrm{ppb}$ in the year 2012 (Hartmann et al., 2013; Saunois et al., 2016a). Current concentration levels are the highest reached in 800000 years (Masson-Delmotte et al., 2013), and emissions and concentrations are likely to continue increasing, making $\mathrm{CH}_{4}$ the second most important greenhouse gas (after $\mathrm{CO}_{2}$ ) that is strongly influenced by anthropogenic emissions (Ciais et al., 2013; Saunois et al., 2016b). In comparison to $\mathrm{CO}_{2}, \mathrm{CH}_{4}$ is characterised by a shorter atmospheric lifetime and a higher warming potential (34 times greater, referring to a period of 100 years and including feedbacks; Myhre et al., 2013). With management of $\mathrm{CH}_{4}$ emissions being identified as a realistic pathway to mit- 
igate climate change effects (Saunois et al., 2016a), quantitative and qualitative insights into processes governing $\mathrm{CH}_{4}$ sources and sinks need to be improved in order to better predict its future feedback with a changing climate.

The Arctic has been identified as a potential future hotspot for global $\mathrm{CH}_{4}$ emissions (Zona et al., 2016), but the effective impact of rapid climate change on the mobilisation of the enormous carbon reservoir currently stored in northern high-latitude permafrost soils remains unclear (e.g. Sweeney et al., 2016; Parazoo et al., 2016; Shakhova et al., 2013; Berchet et al., 2016). Under warmer future conditions, increased thaw depths in Arctic permafrost soils as well as geomorphologic processes such as thermokarst lake formation are expected to mobilise carbon pools from deeper layers (Fisher et al., 2016), while at the same time the activity of methanogenic microorganisms may be promoted. Both factors would contribute to a potential increase in $\mathrm{CH}_{4}$ emissions from permafrost wetlands (Tan and Zhuang, 2015). However, complex feedback mechanisms between climate change, hydrology, vegetation, and microbial communities may partly counterbalance these increased emissions (Kwon et al., 2017; Cooper et al., 2017). In order to improve the reliability of simulated Arctic $\mathrm{CH}_{4}$ emissions under future climate scenarios, several process-based modelling frameworks for predicting $\mathrm{CH}_{4}$ emissions have been improved in recent years (Kaiser et al., 2017; Raivonen et al., 2017), but the confidence in the results remains low, which can also be attributed to a lack of high-quality observational datasets for $\mathrm{CH}_{4}$ emissions from Arctic permafrost wetlands (Ciais et al., 2013).

The eddy covariance (EC) method allows for accurate and continuous flux measurements at the ecosystem scale, but strict theoretic assumptions need to be fulfilled to ensure high-quality observations. Besides the requirement of steady-state conditions and a fully developed turbulent flow field (Foken and Wichura, 1996), the observation of $\mathrm{CH}_{4}$ fluxes in high latitudes requires some special considerations. These include technical challenges related to harsh climate conditions in remote areas of the high northern latitudes (Goodrich et al., 2016), and also problems related to atmospheric phenomena such as very stable stratification that inhibits turbulent exchange during polar winter. Methodological difficulties specific to $\mathrm{CH}_{4}$ also play a role: since net $\mathrm{CH}_{4}$ emissions are not only dependent on the production conditions for $\mathrm{CH}_{4}$ in the soil, but also on the transport processes from soil to atmosphere, they are characterised by higher temporal variability, compared to $\mathrm{CO}_{2} . \mathrm{CH}_{4}$ release through ebullition (Peltola et al., 2017; Hoffmann et al., 2017), i.e. episodic outgassing in the form of bubbles, typically occurs in events of only a few minutes in length, much shorter than the common averaging interval for $\mathrm{EC}(30 \mathrm{~min}) . \mathrm{CH}_{4}$ ebullition events that simultaneously occur within large fractions of the tower footprint thus hold the potential to violate the steady-state assumption for EC. Also, continuous emissions may lead to the accumulation of methane pools close to the ground during periods of very stable stratification, and their instantaneous venting towards higher levels linked to changes in atmospheric conditions may cause pronounced spikes in the signal that violate the EC assumptions. Both cases would lead to systematic biases in EC flux calculations because of an incorrect Reynolds decomposition. As a consequence, high-emission events are likely to be discarded from the time series as very low quality data, or outliers, which has the potential to systematically underestimate long-term $\mathrm{CH}_{4}$ budgets (Wik et al., 2013; Bastviken et al., 2011; Glaser et al., 2004).

To constrain potential systematic biases in EC data that are related to the aforementioned effects, a direct comparison with other observation techniques such as ecosystem chambers can be used. Experiments involving parallel observations with both approaches have been conducted (e.g. McEwing et al., 2015; Emmerton et al., 2014; Sachs et al., 2010; Merbold et al., 2009; Corradi et al., 2005). Chamber measurements are capable of resolving small-scale $\mathrm{CH}_{4}$ emissions properly, but in most cases they cover only a small area on the order of up to a few metres squared. Furthermore the installation of the chamber as well as its operation could introduce disturbances to the study area, which might lead to biased results. Upscaling approaches from the chamber to the EC footprint scale already exist (e.g. Zhang et al., 2012), but until now no method has been presented that aims to calculate $\mathrm{CH}_{4}$ fluxes directly from high-frequency EC measurements with a time resolution of about 1 min.

As a second approach to evaluate potential systematic biases in $\mathrm{EC} \mathrm{CH}_{4}$ fluxes, a different calculation method can be applied to high-frequency atmospheric observations that does not require the theoretic assumptions that limit the applicability of EC (Schaller et al., 2017b). Wavelet analyses provide this option (e.g. Collineau and Brunet, 1993a; Katul and Parlange, 1995), since they can be applied to calculate fluxes for time windows smaller than 10 to $30 \mathrm{~min}$ due to wavelet decomposition in time and frequency domain without ignoring flux contributions in the low-frequency range. Moreover, wavelet transformation does not require steadystate conditions (Trevino and Andreas, 1996) but can also be applied on time series containing non-stationary power (e.g. Terradellas et al., 2001). As a drawback, the calculation of fluxes using wavelet transform requires considerably more computational resources even when a windowed approach is used.

The focus of the present study is on the interpretation of $\mathrm{CH}_{4}$ emission events detected by a wavelet software package (Schaller et al., 2017a, b), which has already successfully been applied to the non-steady-state fluxes during a solar eclipse (Schulz et al., 2017) or to $\mathrm{CH}_{4}$ fluxes from a shallow lake containing ebullition (Iwata et al., 2018). This approach, which builds on the raw data sampled by EC towers, allows us to resolve fluxes not only over 30 min averaging periods, but also for an averaging interval of $1 \mathrm{~min}$. Such a higher temporal resolution facilitates detection of the exact 
time and duration of non-stationary $\mathrm{CH}_{4}$ release events. The obtained results can be directly compared against EC fluxes, where a good agreement has been shown for times with welldeveloped turbulence conditions. We present an analysis of whether peak $\mathrm{CH}_{4}$ emission events at timescales on the order of minutes can be found in the results, and what their basic characteristics are. Finally the study aims to find meteorological triggers that could cause the observed events to occur.

\section{Material and methods}

\subsection{Study site}

Field work was conducted at an observation site within the floodplain of the Kolyma River $\left(68.78^{\circ} \mathrm{N}, 161.33^{\circ} \mathrm{E}, 6 \mathrm{~m}\right.$ above sea level), situated about $15 \mathrm{~km}$ south of the town of Chersky in north-eastern Siberia (Kittler et al., 2016; Kwon et al., 2017). The site is classified as wet tussock tundra underlain by continuous permafrost, with very flat topography. Averaged over the period 1960-2009, the mean annual temperature was $-11^{\circ} \mathrm{C}$, and the average annual precipitation amounts to $197 \mathrm{~mm}$ (Göckede et al., 2017).

Two EC towers were installed in summer 2013 about $600 \mathrm{~m}$ apart, one of them (tower 1) focusing on an artificially drained section of the tundra site, the other (tower 2) serving as a control site to monitor undisturbed conditions. Both systems were equipped with the same instrumentation set-up, including a heated sonic anemometer (uSonic-3 scientific, METEK GmbH) and a closed-path gas analyser (FGGA, Los Gatos Research Inc.), and feature about the same observation height (tower 1: $4.9 \mathrm{~m}$ a.g.1.; tower 2: $5.1 \mathrm{~m}$ a.g.1.). Due to their proximity, both towers are also exposed to the same meteorological conditions. Inter- and intra-annual variability of the exchange fluxes of $\mathrm{CO}_{2}$ and $\mathrm{CH}_{4}$, including an analysis of related environmental controls, are presented by Kittler et al. (2017b). For more details on the instrumentation set-up, please refer to Kittler et al. (2016, 2017a).

\subsection{Raw data processing and flux calculation}

The raw data on the high-frequency fluctuations of wind and mixing ratios were collected using the software EDDYMEAS (Kolle and Rebmann, 2007) at a sampling rate of $20 \mathrm{~Hz}$. Ancillary meteorological data were acquired at $1 \mathrm{~Hz}$ frequency through the LoggerNet software (Campbell Scientific Inc., Logan, Utah, USA) on a CR3000 Micrologger (Campbell Scientific). Both programs were running on-site on a personal computer, using the local time zone (Magadan time, MAGT: UTC $+12 \mathrm{~h}$ ). The mean local solar noon is $\mathrm{UTC}+13 \mathrm{~h}$. Within the context of this study, datasets within the period 1 June to 15 September 2014 were analysed.

As a first approach to calculate turbulent $\mathrm{CH}_{4}$ fluxes, we employed the EC method using recent recommendations on correction methods and quality assurance measures (Aubi- net et al., 2012). A coordinate rotation into the streamlines (Rebmann et al., 2012) was not applied due to the very flat and homogeneous terrain at both towers. There was no tilt in the alignment of the sonic anemometers at both towers and after a careful inspection of the raw data no disturbances of the streamlines due to the terrain or other influences could be found. This allows the assumption that $\bar{w}=0$ for welldeveloped turbulence. We used the software package TK3 (Mauder and Foken, 2015a, b) for this purpose, which includes all necessary corrections, data quality tests (Foken et al., 2012a), and a spike detection test using the median absolute deviation (MAD, Hoaglin et al., 2000; Mauder et al., 2013). TK3 has been demonstrated to compare well with other available packages (Mauder et al., 2008; Fratini and Mauder, 2014). As the standard for the EC method, we derived turbulent fluxes with an averaging period of $30 \mathrm{~min}$.

Because highly non-steady-state conditions were expected for $\mathrm{CH}_{4}$ fluxes at this observation site, which potentially causes a serious violation of the basic assumptions linked to the EC method (Foken and Wichura, 1996), we applied a wavelet-based calculation method as a second flux processing approach in addition to the standard EC data processing. Schaller et al. (2017b) have developed a method for waveletbased flux computation that offers the possibility of determining fluxes with a user-defined time resolution that can be as low as about $1 \mathrm{~min}$. Within the context of this study, we applied their calculation tool with a continuous wavelet transform using the Mexican hat wavelet $\left(\mathrm{WV}_{\mathrm{Mh}}\right)$, which provides an excellent resolution of the flux in the time domain. It should therefore be the preferred mother wavelet to obtain an exact localisation of single events in time without losing information in the frequency domain (Collineau and Brunet, 1993b). For more details on the direct implementation of the method refer to Schaller et al. (2017b).

For wavelet analysis the spike-corrected (Mauder et al., 2013) raw data of both vertical wind speed $w$ and $\mathrm{CH}_{4}$ mixing ratio $c$ were used. The time series was corrected for a time lag between these parameters by maximisation of the covariances by cross-correlation for every $30 \mathrm{~min}$ interval (Rebmann et al., 2012). As also stated for EC, a coordinate rotation was not applied. Small tilt errors have no significant influences on scalar fluxes (Lee et al., 2004). The cone of influence (COI; Torrence and Compo, 1998) was estimated and all results are based on data not affected by edge effects.

For steady-state conditions, the wavelet and EC method have been shown to be in very good agreement (Schaller et al., 2017b). In the case of non-steady-state conditions with contributing periods $>30 \mathrm{~min}$, the EC quality control tests should flag those cases to be excluded (Foken et al., 2012b). Additionally, in those cases the ogive test (Desjardins et al., 1989; Foken et al., 1995; Oncley et al., 1990) also yields contributions to the flux for periods $>30 \mathrm{~min}$. Besides that, the Mexican hat wavelet will nonetheless yield correct and trustworthy fluxes, also for periods $>30 \mathrm{~min}$, if the chosen integration interval in the period domain is big enough (Percival 
and Walden, 2000; Torrence and Compo, 1998). In this study, the upper integration limit $\lambda_{\max }$ in the period domain was set to $33 \mathrm{~min}$. To account for low-frequency contributions in the case study in Sect. 3.4, a second calculation was conducted, where $\lambda_{\max }=184 \mathrm{~min}$.

\subsection{Detection and classification of events}

\subsubsection{Detection of events}

While spikes within the $20 \mathrm{~Hz}$ raw data were already identified in the MAD test (Mauder et al., 2013), in a first stage of the wavelet-based event detection we conducted an additional MAD test on processed fluxes similar to Papale et al. (2006):

$\langle d\rangle-\frac{q \cdot \mathrm{MAD}}{0.6745} \leq d_{i} \leq\langle d\rangle+\frac{q \cdot \mathrm{MAD}}{0.6745}$,

where

$d_{i}=\left(x_{i}-x_{i-1}\right)-\left(x_{i+1}-x_{i}\right)$

parameterises the difference of the current value $x_{i}$ to the previous and next value in time. $\langle d\rangle$ denotes the median of all those double differenced values and

$\mathrm{MAD}=\left\langle\left|d_{i}-\langle d\rangle\right|\right\rangle$.

Due to its robustness the median absolute deviation is a very good measure of the variability of a time series and substantially more resilient to outliers than the standard deviation (Hoaglin et al., 2000). The test was applied to Mexican hat wavelet flux with a time step of $\Delta t=30 \mathrm{~min}$. If a value $d_{i}$ in the time series exceeded the given range in Eq. (1), it was detected as an event. A threshold value of $q=6$ was found to be suitable to reliably separate events from periods with a regular exchange flux between surface and atmosphere.

The same MAD test calculations have also been applied to the flux with averaging interval $\Delta t=1 \mathrm{~min}$. The purpose of this higher-resolution analysis was first to precisely constrain the duration of an event down to the resolution of minutes, and second to allow the detection of exact start and end times of events. We defined here a minimum duration of 2 min for an event, since this way we could avoid labelling a sequence of high-frequency spikes, which sometimes pass the TK3 spike detection threshold, as an event.

\subsubsection{Classification of events}

The approach described above only detects 1 min steps belonging to an event, but does not provide any knowledge about typical structures of such contiguous single events. The term "structure" in this context refers to the specific sequence of consecutive 1 min flux values that together form the event: in a simple case, flux rates regularly increase until reaching a plateau, then drop back to their starting values, with no events directly before or afterwards. More complex events appear as clusters; i.e. during a prolonged period of time several shorter events occur close to each other. Since events with different structure may also be triggered by different atmospheric conditions, we developed a basic classification to differentiate types of events consisting of adjacent 1 min steps.

Based on the single event minutes identified by the MAD test, a manual search for characteristic, repeating patterns within all half-hour intervals that contained events resulted in the definition of three typical event structures. In this context, it was found that the MAD test for a threshold value of 4 or 6 was not always able to resolve the whole event (blue plus signs within grey shaded event duration in Fig. 1), and thus in such cases the actual starting and ending times of an event were corrected manually.

We labelled the first event type a single "peak event". For this category, in the simplest case the flux increased monotonically up to one maximum event peak or a plateau with high flux rates, followed by a monotonic decrease back to base level. No other events were detected within $30 \mathrm{~min}$ before or after the single-peak event. As the example (Fig. 1a) shows, such an ideal sequence cannot be expected in general, but in all cases a pattern of coherent single event minutes showing the tapering to one peak or a few subsequent local maxima clearly suggested the classification of a peak event. Peak events can occur as either negative or positive outliers from the baseline flux. If a positive peak was followed or preceded by a negative one or vice versa, both were combined into a single peak event as long as the magnitude of the second peak was lower than one quarter that of the main peak.

We termed the second event class "down-up" events. Down-up events had the same basic properties as singlepeak events, but in contrast they consisted of one sharp negative and positive peak each, which were of similar magnitude (Fig. 1b). If the order of the two peaks was reversed, the process was called an "up-down" event. Typically the two extremes within a down-up event were separated by several minutes (e.g. 04:58 and 05:01 in Fig. 1b), and such (nonextreme) transition periods were frequently not labelled as events by the MAD test because they did not exceed the threshold for event detection. In this case these event minutes needed to be manually added to form a coherent downup/up-down event.

The third class of events in our classification scheme was called "clusters". In this category we collected all events that did not meet the criteria defined above for single-peak events or down-up events, instead showing a coherent pattern but not an unambiguous structure. This was generally the case for longer event periods that were potentially formed by the merging of several consecutive shorter events (Fig. 1c). However, in these cases a clear distinction between individual events was impossible due to the close succession of events over time, and the associated partial overlap. Accordingly, the identification of meteorological triggers for single events (see also Sect. 3.4) was also impeded, since more than one 

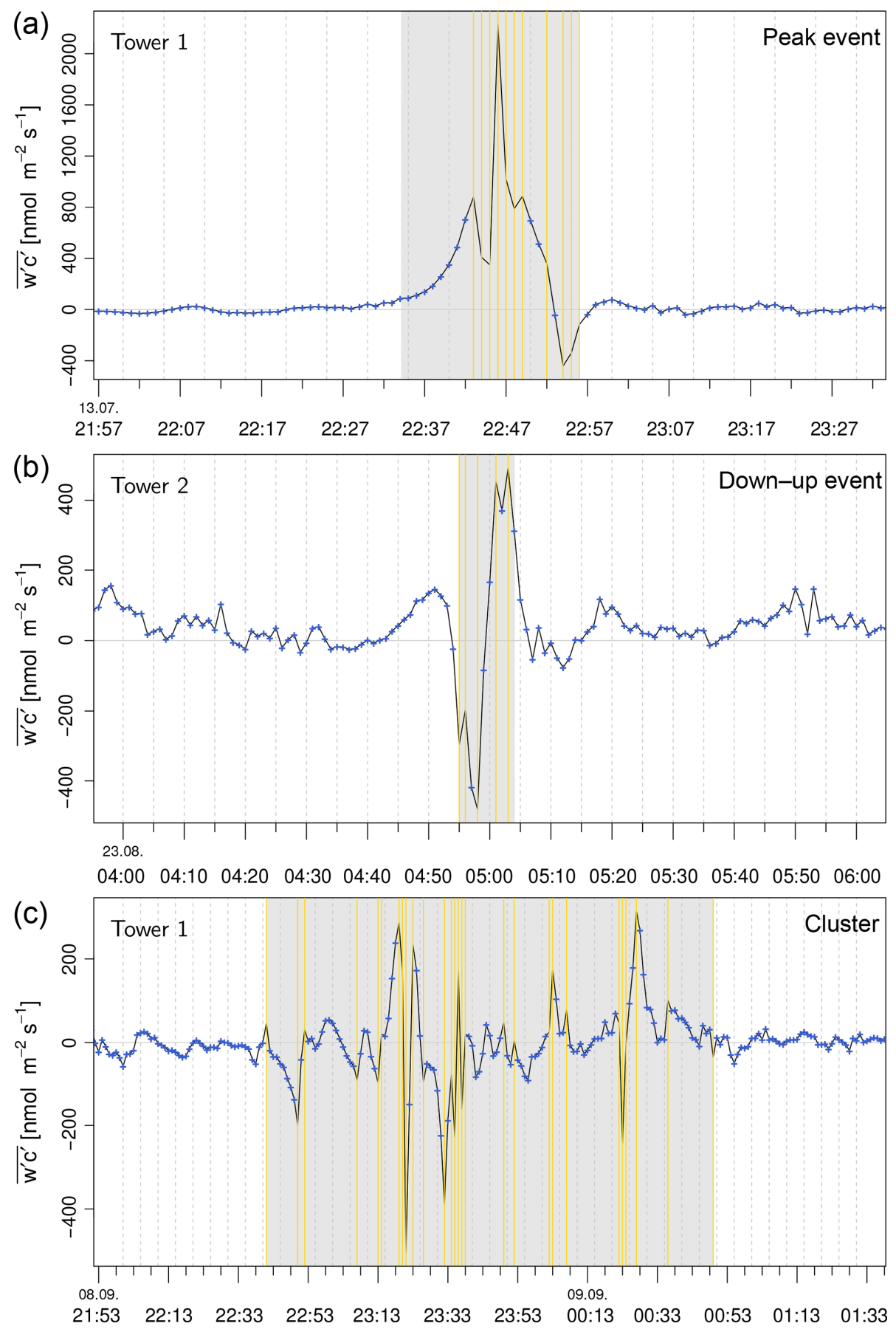

Figure 1. Examples for peak events (a), down-up events (b), and clustered events (c) identified using the Mexican hat wavelet flux. Data points marked with a yellow vertical line were detected as event minute using the MAD test with threshold $q=6$, while all other non-event data were marked with blue plus signs. The manually detected event length is shaded in grey colour.

trigger may have been involved. We therefore handled the classification of events very conservatively, assigning singlepeak or up-down/down-up events only in very clear cases, while all remaining events were labelled clusters.

\subsubsection{Linking events to meteorological conditions}

For all events detected within the observation period, computed flux rates as well as prevalent meteorological conditions before, during, and after the event were collected in a database. These conditions were available as parameters in 
four different aggregation time steps: (1) $\mathrm{CH}_{4}$ flux rates from both EC and wavelet processing as well as friction velocity $\left(u_{*}\right)$ were used at $30 \mathrm{~min}$ intervals. (2) Longwave radiation budget $(I)$, air temperature $(T)$, relative humidity $(\mathrm{RH})$, and air pressure ( $p$ ) came in $10 \mathrm{~min}$ time steps. (3) $1 \mathrm{~min} \mathrm{CH}_{4}$ flux rates were available from the high-resolution wavelet processing. Finally (4) wind speed $(U), \mathrm{CH}_{4}$ mixing ratios $\left(c_{\mathrm{CH}_{4}}\right)$, and wind direction (WD) were taken from $20 \mathrm{~Hz}$ raw data. Averages for the period during the event were aggregated between start and end times of the detected event, while for the periods before and after the event mean values were derived for $10 \mathrm{~min}$ intervals before the event start or after the event end, respectively. Regarding the coarser resolution datasets (1) and (2), in each case the time step that overlapped most with the target time frame before, during, and after the event was chosen.

\section{Results}

\subsection{Event statistics}

Most statistics in this section are based on the number of minutes that were identified as part of an event. Using a flux averaging interval of $\Delta t=1 \mathrm{~min}$, these minutes were defined as values failing the MAD test. For this analysis, the study period from 1 June to 15 September 2014 was split into seven blocks with a length of half a month each.

Our event detection algorithm identified 49 events for each site during the given observation period. Of these events, 28 (tower 1) and 23 (tower 2) were classified as clusters, while at both towers 6 events showed the typical shape of an up-down or down-up event. Including interpolation between event minutes detected by the MAD test, the cluster events covered a combined period of 65 (tower 1 ) and $49 \mathrm{~h}$ (tower 2), with a minimum duration of 49 and $31 \mathrm{~min}$, and a maximum duration of 410 and $329 \mathrm{~min}$. All clusters and up-down/down-up events occurred exclusively during nighttime (21:00-09:00 MAGT).

The remaining 15 (tower 1) and 20 (tower 2) events were characterised as single-peak events. Only 4 of these occurred during daytime (09:00-21:00 MAGT), on 12 and 15 June 2014, while all other events occurred at night. The duration of these peak events ranged between 2 and $43 \mathrm{~min}$, while about half of them lasted between 9 and $21 \mathrm{~min}$. All peak events occurred simultaneously with an event at the other tower, i.e. a corresponding counterpart event at the other tower was observed at about the same time. We will subsequently refer to simultaneous events (one from each tower) as a "pair" of events, while "event" still denotes one event from a single tower. For 13 event pairs, both events were classified as "peak events", while the majority of the remaining peak and up-down events were paired with cluster events at the other tower.
The absolute number of detected event minutes differed strongly between the two towers. At tower 1, their cumulative duration exceeded that observed at tower 2 by a factor of 1.4 (first half of September) to 2.8 (first half of August). As one example, in the first half of August 462 min were identified by the MAD test as being part of an event at tower 1, surpassing just 165 event minutes detected at tower 2 by a wide margin. Summed up for the period 1 June to 15 September, a total of 1078 event minutes were detected for tower 1 , more than doubling the cumulative sum at tower 2 (539 min). An explanation for this difference can be found in the statistical characteristics of the wavelet flux for both towers: at tower 1 $7.7 \%$ of all data were out of the range from $Q_{1}-1.5\left(Q_{3}-Q_{1}\right)$ to $Q_{3}+1.5\left(Q_{3}-Q_{1}\right)$, where $Q_{1}$ denotes the $25 \%$ quantile and $Q_{3}$ the $75 \%$ quantile. At tower $25.4 \%$ of the data are out of this range, i.e. tower 2 had $2.3 \%$ more extreme outliers (values that exceeded the interquartile range by a factor of 1.5) compared to tower 1. As the median absolute deviation is resilient regarding outliers, the MAD test is a robust outlier classifier even if one dataset contains more outliers than another one (Hoaglin et al., 2000).

\subsection{Event seasonality}

For both towers, the relative distribution of events over the summer season showed similar patterns: the largest proportion of all events was detected in the first half of August (37.9\% and $30.6 \%$ at towers 1 and 2). Earlier in the growing season, we observed a gradual increase in event occurrence from only a few percent in the first half of June to $19.3 \%$ (tower 1) and $16.5 \%$ (tower 2) in the second half of July. Following the maximum in early August, the appearance of events decreased rapidly to a range between $5.9 \%$ and $15.4 \%$ per half-month in late August-September.

Seasonal courses in event frequency appear to be linked to trends in soil thermal conditions, as indicated by, for example, the simultaneous drop in both event minutes and mean soil temperatures in late August. At the control site, the median half-monthly soil temperature at $-8 \mathrm{~cm}$ depth gradually increases from $3.6^{\circ} \mathrm{C}$ in the second half of June to its maximum at $5.1^{\circ} \mathrm{C}$ in the first half of August, followed by the aforementioned steep drop to $3.3^{\circ} \mathrm{C}$ in the second half of August (details in Kittler et al., 2016, for example). Both the general shape of the seasonal course and the timing of the peak agree with the detected seasonality in event flux percentages.

The observation from Sect. 3.1 that peak events were exclusively detected simultaneously with an event at the other tower suggests that events are typically not triggered by local changes in soil effluxes, but rather by mesoscale meteorological effects. The correlation found between event frequency and soil thermal conditions does not contradict that: a higher $\mathrm{CH}_{4}$ emission rate from soil in times where the ground layers are (partly) decoupled from the EC level will result in a bigger amount of pooled $\mathrm{CH}_{4}$ in a certain time - and conse- 
quently also cause a bigger flux when flushed up to the EC system.

\subsection{Links between events and meteorological conditions}

Due to their precise temporal delimitation, the class of peak events allowed a clear characterisation of conditions for the periods before, during, and after events. Accordingly, based on the study of peak events we were able to correlate event occurrence with short-term shifts in meteorological conditions that may be responsible for triggering the observed peak events. The following paragraphs list statistics on the most relevant potential influence factors.

The air temperature $(T)$ measured at the top of the towers monotonically decreased in at least $60 \%$ of all peak events (21 of 35). This temperature drift usually started more than $10 \mathrm{~min}$ before the event, and persisted until at least $10 \mathrm{~min}$ after the event. Temperature change in time in this context ranged between $-0.04 \mathrm{~K} \mathrm{~min}^{-1}$ within an $18 \mathrm{~min}$ interval and $-0.27 \mathrm{~K} \mathrm{~min}^{-1}$ within a $22 \mathrm{~min}$ interval. The opposite case of increasing air temperatures during a peak event was detected only once. For the relative humidity (RH) at the top of the tower, in at least $29 \%$ ( 10 of 35) of all peak event cases a monotonic increase was observed within the timespan of at least $10 \mathrm{~min}$ before and after the event. Increase rates for this subset of events are within the range $+0.67 \% \mathrm{~min}^{-1}$ within $9 \mathrm{~min}$ to $+0.86 \% \mathrm{~min}^{-1}$ within $22 \mathrm{~min}$. To give an example, during the peak event that started on 13 July at 22:39 MAGT, and had a total length of $22 \mathrm{~min}$, the temperature dropped by $5.9 \mathrm{~K}$ in total, while the relative humidity increased by $19 \%$. No case was observed where the relative humidity decreased significantly during an event.

The wind speed $(U)$ increased in $83 \%$ of all cases (29 of 35) during a peak event, in comparison to the last $10 \mathrm{~min}$ before the occurrence. In $48 \%$ (14 of 29) of these situations, however, $U$ decreased again right after the event. The largest increase in wind speed was found to be $7.4 \mathrm{~m} \mathrm{~s}^{-1}$, while for the majority of cases the difference between the time before and during the event ranged from 0.2 to $2.1 \mathrm{~m} \mathrm{~s}^{-1}$. The vertical wind speed $(w)$, which is a direct part of all flux calculation methods, remained very close to the ideal value of zero in all these cases. Still, minor variations within a very narrow range of absolute values showed a very similar pattern, i.e. in $74 \%$ ( 26 of 35) of the peak events a temporary increase was observed, followed by a decrease in $54 \%$ of these cases $(14$ of 26). The friction velocity $\left(u_{*}\right)$ increased at the beginning of $94 \%$ (33 of 35) of all peak events, and decreased again right afterwards in $76 \%$ ( 25 of 33 ) of these cases. For half of these events, only a moderate increase in the friction velocity was observed $\left(<0.1\right.$ to $\left.0.3 \mathrm{~m} \mathrm{~s}^{-1}\right)$, while the full range of shifts lay between $<0.01$ and $0.7 \mathrm{~m} \mathrm{~s}^{-1}$.

For the stability of atmospheric stratification $\left(z L^{-1}\right.$, with $z$ as measurement height and $L$ as Obukhov length), no general pattern for the conditions before, during, and after a peak event could be found. In $43 \%$ of all events $(15 / 35)$ there was no change in stability over time while the event occurred. For 7 cases, the stability during the $30 \mathrm{~min}$ interval where the event occurred shifted towards more unstable stratification, while for 8 cases a change in the opposite direction was observed. About $23 \%$ (8 of 35) of all events occurred during unstable stratification $\left(z L^{-1}<-0.0625\right)$, exceeding the average data fraction of unstable stratification during night time (13\% for tower $1,18.5 \%$ for tower 2$)$. Due to the site being located in the high Arctic latitudes, (slightly) unstable stratification was also likely to occur at night as long as the shortwave downwelling radiation $K \downarrow>20 \mathrm{~W} \mathrm{~m}^{-2}$. The stability before, during, and after daytime events was always neutral $\left(-0.0625 \leq z L^{-1} \leq 0.0625\right)$.

Summarising, since the majority of events were detected during the night (21:00-09:00 MAGT), it could be expected that a large number of cases would be subject to systematically falling temperatures, and associated increases in relative humidity. On the other hand, the high percentage of peak events that are characterised by an increase and subsequent decrease in wind speed and friction velocity indicates that turbulence intensity in the atmospheric surface layer is a major influence factor. With a higher-than-average fraction of cases with neutral atmospheric stability associated with peak events, it can be speculated that such stratification conditions promote the impact of sporadic increases in mechanically generated turbulence that lead to the high $\mathrm{CH}_{4}$ emissions.

\subsection{Case study: night-time advection}

To demonstrate the characteristics of a typical peak event, as well as the approach we used herein to analyse and interpret it, the following sub-sections provide a detailed description of a case study during the night from 2 to $3 \mathrm{Au}-$ gust 2014. That event was already described by Schaller et al. (2017b) to show that wavelet analysis is able to resolve that event. Schaller et al. (2017b) discussed the calculation method, comparing both the Mexican hat and the Morlet mother wavelet, and showed that the Mexican hat was able to resolve the event precisely in time. Based on that finding, we show the meteorological conditions and analyse them to identify the underlying triggering mechanism. We chose this particular event because conditions are well documented through photographs taken by the observer, which strongly support our theory about the underlying triggering mechanism as described later in this section.

\subsubsection{Meteorological conditions during event period}

Within the given night, at both tower 1 (Fig. 2) and tower 2 (similar general patterns, data not shown) no signs of an upcoming event could be registered until 23:30 MAGT. Starting at 23:00 MAGT, a light breeze from the south-east with a maximum wind speed around $1.5 \mathrm{~m} \mathrm{~s}^{-1}$ gradually decreased to a calm. The mean $\mathrm{CH}_{4}$ concentrations in this half-hour 
were 2102 and $2112 \mathrm{ppb}$ at towers 1 and 2 , and the friction velocity as a proxy measure for aerodynamically generated turbulent motion was very low $\left(<0.1 \mathrm{~m} \mathrm{~s}^{-1}\right)$. At 23:31 MAGT, both towers registered an increase in $\mathrm{CH}_{4}$ concentrations, associated with a minor increase in the wind speed. A temporary shift in wind direction to the north-west was reversed back to the south-east after a few minutes.

Around 23:45 MAGT, the wind speed continued increasing to about $1.5 \mathrm{~m} \mathrm{~s}^{-1}$, and a few minutes later the wind direction turned to the east-north-east. The onset of the event itself was detected at 23:55 (tower 1, Fig. 3) and 23:59 MAGT (tower 2, Fig. 4), and this period of high fluxes lasted until 00:18 (tower 1) and 00:07 MAGT (tower 2). During the time interval 23:30 to 23:59 MAGT when the event started, the half-hourly averaged friction velocity $u_{*}$ increased substantially, disrupting the previously existing decoupling of surface and higher atmosphere due to stable stratification. This increased turbulence intensity potentially vented $\mathrm{CH}_{4}$ pools that had accumulated near the ground towards the EC systems at tower top. Shortly after the end of the event, the wind direction at both towers changed from the east back to the south-east, i.e. the same direction as before the event. The $\mathrm{CH}_{4}$ concentrations also decreased. Wind speeds, on the other hand, did not decrease, while the friction velocity decreased marginally.

\subsubsection{Wavelet fluxes during event period}

The mean Mexican hat $\mathrm{CH}_{4}$ flux rate during the event was calculated as $181 \mathrm{nmolm}^{-2} \mathrm{~s}^{-1}$ at tower 1 (tower 2: $392 \mathrm{nmol} \mathrm{m}^{-2} \mathrm{~s}^{-1}$ ). This value is substantially higher than the $7 \mathrm{nmolm}^{-2} \mathrm{~s}^{-1}$ observed in the $20 \mathrm{~min}$ period before the event (tower 2: $26 \mathrm{nmolm}^{-2} \mathrm{~s}^{-1}$ ) as well as the $19 \mathrm{nmol} \mathrm{m}^{-2} \mathrm{~s}^{-1}$ in the $20 \mathrm{~min}$ period after the event (tower 2: $88 \mathrm{nmol} \mathrm{m}^{-2} \mathrm{~s}^{-1}$ ). The relatively high mean flux rate after the event at tower 2 is caused by a short period of higher fluxes up to 00:20 MAGT. In addition to the average flux rates, the standard deviation of fluxes at tower 1 $\left(118 \mathrm{nmol} \mathrm{m}^{-2} \mathrm{~s}^{-1}\right)$ also significantly exceeded the values before $\left(53 \mathrm{nmolm}^{-2} \mathrm{~s}^{-1}\right)$ and after $\left(31 \mathrm{nmolm}^{-2} \mathrm{~s}^{-1}\right)$ the event (tower 2 showed similar overall behaviour).

The exact times when the flux peaks occurred coincided with the highest energy and most positive contribution to the wavelet flux, as indicated in the wavelet cross-scalograms of both towers (Figs. 3, 4). Sensitivity studies revealed that the choice of the upper wavelet scale integration limit $J$ (Eq. 13 in Schaller et al., 2017b) and thus the maximum wavelet period $\lambda_{\max }$ significantly impacts the flux computation: an extension of the upper period integration limit to $\lambda_{\max }=184$ min showed a significant increase in the wavelet flux. Still, we did not find any indication that hinted at an influence of gravity waves during this particular case study. The Mexican hat cross-scalogram (Fig. 5) generated a sharp temporal transition between periods of high and low flux contributions, and this separation allowed us to precisely con-
Table 1. Mean flux rates during the $30 \mathrm{~min}$ period that hosted the peak event discussed in the case study, as detected by two different flux processing approaches. All flux values are given in $\mathrm{nmolm} \mathrm{m}^{-2} \mathrm{~s}^{-1}$.

\begin{tabular}{lrr}
\hline Approach & Tower 1 & Tower 2 \\
\hline Eddy covariance & 161 & 213 \\
Mexican hat wavelet & 109 & 179 \\
\hline
\end{tabular}

strain the duration of the event, where the low-frequency periods from 40 to $180 \mathrm{~min}$ contributed most to the total flux.

For both flux processing approaches compared herein, average $\mathrm{CH}_{4}$ flux rates for the $30 \mathrm{~min}$ interval that contained the peak event are summarised in Table 1 . These results indicate that for the chosen event period, the Mexican hat wavelet yielded systematically lower fluxes compared to the EC reference. These differences from the EC fluxes suggest that regular EC data processing yielded biased results caused by non-stationary conditions, if these EC periods were not filtered out and gap filled.

\subsubsection{Cold-air advection from mountains}

Around 23:45 MAGT, the first signs of a developing ground fog were observed and also documented by photographs. Additional pictures were taken during the following minutes near tower 2 (Fig. 6, top), i.e. around the time the events began. All pictures demonstrate a ground fog moving in from the north-east, where the ridges of two nearby hills, Mount Rodynka (351 m a.s.l.) and Mount Panteleicha (632 m a.s.l., Fig. 7), are located. The time at which this fog reached tower 1 coincided well with the onset of the events. Shortly after midnight, another photograph (00:11 MAGT) demonstrates that the fog had largely disappeared, well aligned with the sharp decrease in flux magnitude that indicates the end of the event.

The observed ground fog was also reflected in the meteorological data (Fig. 2). During the slow build-up of the ground fog in the period between 23:20 and 23:50 MAGT, the temperature at $2 \mathrm{ma}$ a.g. decreased by $1.3 \mathrm{~K}$, while the relative humidity showed a small increase in the same timespan. Within the same period, the longwave net radiation, which is a good measure of the temperature difference between the sky and the ground, decreased to minimum values of $23 \mathrm{~W} \mathrm{~m}^{-2}$, which implies a low temperature difference between the surface and the clouds, indicating very low clouds or fog.

\subsection{Event triggers}

Our statistics on meteorological conditions before, during, and after the detected peak events reveal a common pattern for all event situations, regardless of the mechanism that actually triggered the event: during a period of weak turbu- 


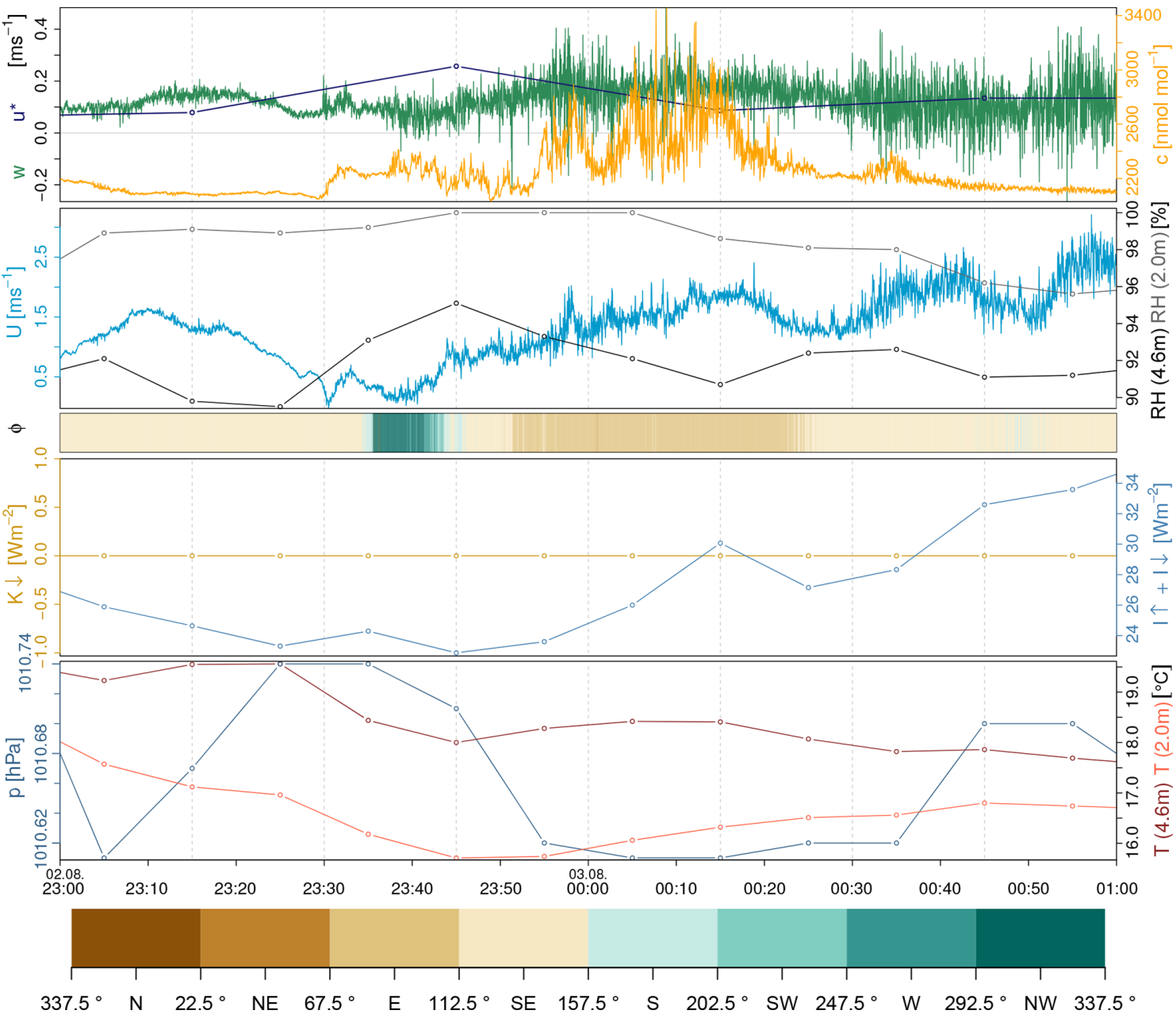

Figure 2. Meteorological conditions observed at tower 1 during the case study event of 2-3 August 2014. Wind velocity $U$, vertical wind speed $w$, and $\mathrm{CH}_{4}$ mixing ratio $c$ as well as wind direction $\phi$ are shown in a time resolution of $20 \mathrm{~Hz}$. The friction velocity $u *$ was averaged to $30 \mathrm{~min}$, while all other data were averaged to $10 \mathrm{~min}$ : relative humidity $\mathrm{RH}$ and air temperature $T$ (both in each 2.0 and $4.5 \mathrm{~m}$ a.g.l.) as well as the longwave radiation balance $I \downarrow+I \uparrow$, the shortwave downwelling radiation $K \downarrow$, and air pressure $p$. The bottom panel shows a legend for $\phi$.

lence, the surface was at least partially decoupled from the lower atmosphere where the flux sensors were positioned. $\mathrm{CH}_{4}$ that was emitted from the soil during this period could not properly be mixed up to the sensor level, therefore likely forming a $\mathrm{CH}_{4}$-rich layer of air near the ground. In all event cases, either a general change in atmospheric conditions or a short-term meteorological phenomenon broke up the decoupling between the layers. As a consequence, the $\mathrm{CH}_{4}$ pool in near-surface air layers was vented up to the EC level, and therefore detected as a pronounced peak in the flux rate.

This sequence of conditions strongly suggests that atmospheric mixing, and not $\mathrm{CH}_{4}$ emissions processes from the soil, is the dominating mechanism behind the flux peak events as detected by our algorithm. Since we did not observe a single case study where a strong flux peak was detected within a previously well-mixed situation, our findings indicate that ebullition events, which can for example be detected at smaller scales with soil chambers (e.g. Kwon et al., 2017), are usually too small as individual emissions, or not coordinated enough spatially across the relatively large footprint area (approx. $4000 \mathrm{~m}^{2}$ at neutral stratification) to be detected by this EC set-up with a sensor height $\geq 4.9 \mathrm{~m}$ a.g.l. Following the detailed description of the case study presented in the preceding section, in the subsections below we briefly discuss several typical meteorological situations that were also observed to trigger events. Although there were no additional boundary layer or gradient measurements available, all identified mesoscale phenomena in the following subsections were always clearly visible at both towers, which supports the findings. 


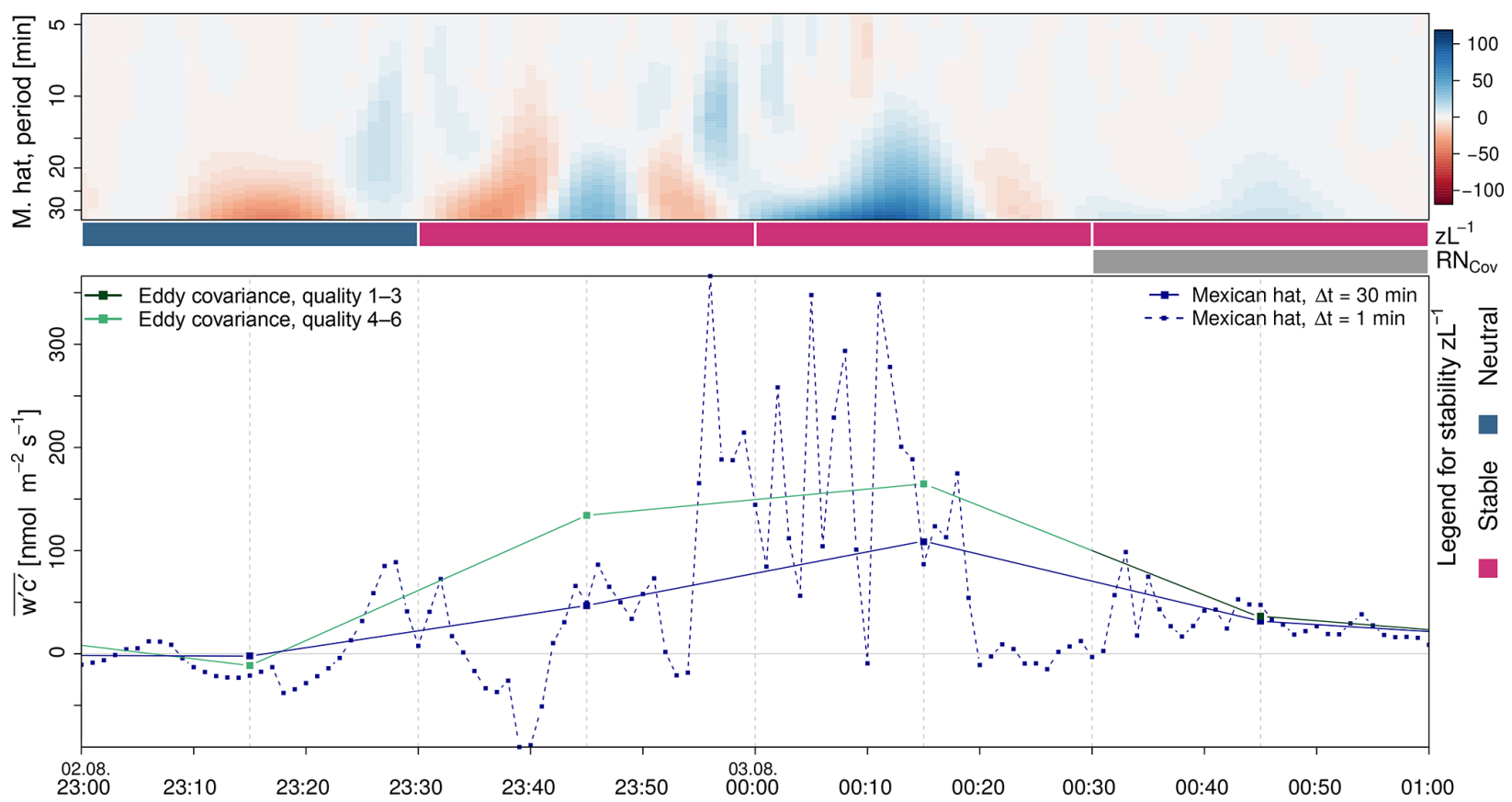

Figure 3. Wavelet cross-scalogram and flux rates computed for tower 1 during the case study event on 2-3 August 2014. The colours in the wavelet cross-scalogram between $w$ and $c$ denote the flux intensity (wavelet coefficient), where intensive colours indicate higher flux contributions downwards (negative, dark red) or upwards (positive, blue). The whole scalogram is outside the cone of influence (COI). Atmospheric stratification $z L^{-1}$ (Foken et al., 2004) for every 30 min interval was denoted as a blue (neutral) or pink (stable) colour bar right below the cross-scalogram. Grey-coloured intervals in the line labelled $\mathrm{RN}_{\mathrm{Cov}}$ refer to best steady-state $\left(\mathrm{RN}_{\mathrm{Cov}}<30 \%\right)$ conditions according to Foken et al. (2004). The quality classes 1-9 in the bottom panel for EC refer to the overall flux flagging system after Foken et al. (2004).

\subsubsection{Cold-air drainage}

At the Chersky floodplain sites, about $50 \%$ of all events occurred with wind directions from the E-NE, while only $3 \%$ of all events fell into the S-SE (Table 2). These observations are in stark contrast to the local wind climatology, which lists just $16.2 \%$ of cases in the E-NE sector, while the S-SE sector dominates with $37.9 \%$ (values based on observations from tower 1, averaged for whole observation period). An explanation for this discrepancy can be found in the mesoscale wind field at this particular location, which may be prone to katabatic winds from the E-NE sector at night: typically, night-time events from these sectors are characterised by decreases in the longwave net radiation $I$ to values around or below $20 \mathrm{~W} \mathrm{~m}^{-2}$ exactly during or a short time after the event. This observation indicates that temperature differences between above and below the net pyrgeometer rapidly decreased, which could be a sign for low-level fog layers moving through.

\subsubsection{Weather fronts}

Weather fronts are typically associated with substantial shifts in, for example, air temperature, wind speed, or wind direction. As an example, we observed such signs of a weather front passing the site on 12 June 2014, where the previously falling air pressure started increasing rapidly by $1 \mathrm{hPa}$ per hour, combined with a wind speed increase from about 5 to $10 \mathrm{~m} \mathrm{~s}^{-1}$. With the stability of atmospheric stratification being neutral during this daytime event, it is unlikely that the mechanical turbulence associated with the frontal passage ejected $\mathrm{CH}_{4}$ pools that had previously been accumulated close to the ground. Instead, it can be speculated that pressure fluctuations associated with the stronger turbulence washed out $\mathrm{CH}_{4}$ from micropores within the top soil layers. However, particularly at night an accumulated $\mathrm{CH}_{4}$ pool close to the surface should be the most likely source for a peak event, as observed during the night of 13 June 2014 for example. Here the wind speed increased rapidly from about 1 to $4 \mathrm{~m} \mathrm{~s}^{-1}$, breaking up decoupled air layers between the surface and sensor level, and in the process venting the $\mathrm{CH}_{4}$ that had previously been accumulated over time. This event was registered as rapidly shifting $\mathrm{CH}_{4}$ mixing ratios at the tower top, which decreased within $10 \mathrm{~min}$, while the wind speed continuously remained high.

\subsubsection{Atmospheric gravity waves}

For one pair of events occurring on 12 July 2014, conditions at both towers indicated low atmospheric turbulence 


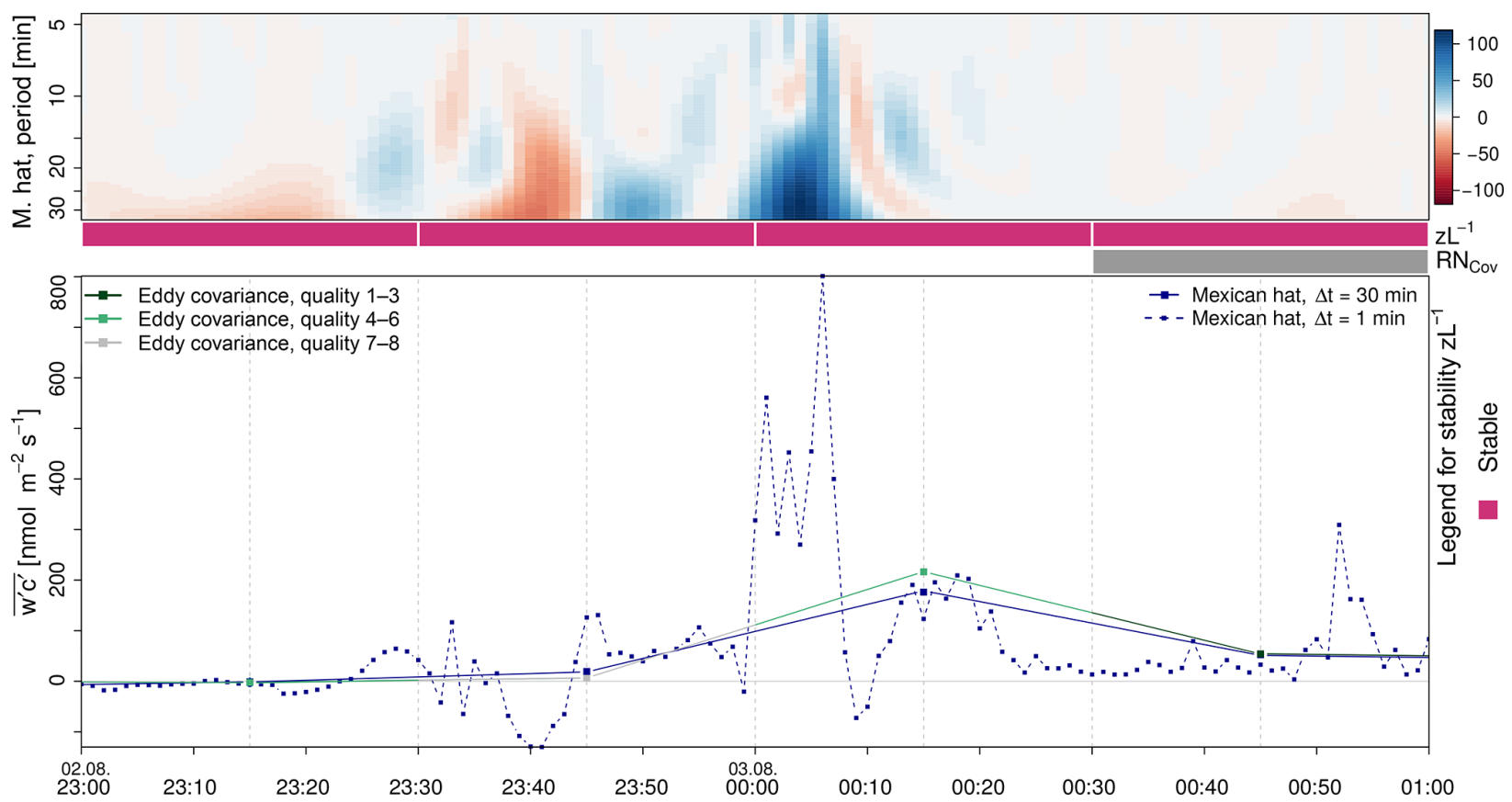

Figure 4. Wavelet cross-scalogram and flux rates computed for tower 2 during the case study event on 2-3 August 2014. The colours in the wavelet cross-scalogram between $w$ and $c$ denote the flux intensity (wavelet coefficient), where intensive colours indicate higher flux contributions downwards (negative, dark red) or upwards (positive, blue). The whole scalogram is outside the cone of influence (COI). Atmospheric stratification $z L^{-1}$ (Foken et al., 2004) for every $30 \mathrm{~min}$ interval was shown as coloured bars right below the cross-scalogram and stable (pink coloured) during the complete time. Grey-coloured intervals in the line labelled $\mathrm{RN}_{\mathrm{Cov}}$ refer to best steady-state $\left(\mathrm{RN}_{\mathrm{Cov}}<\right.$ $30 \%$ ) conditions according to Foken et al. (2004). The quality classes 1-9 in the bottom panel for EC refer to the overall flux flagging system after Foken et al. (2004).

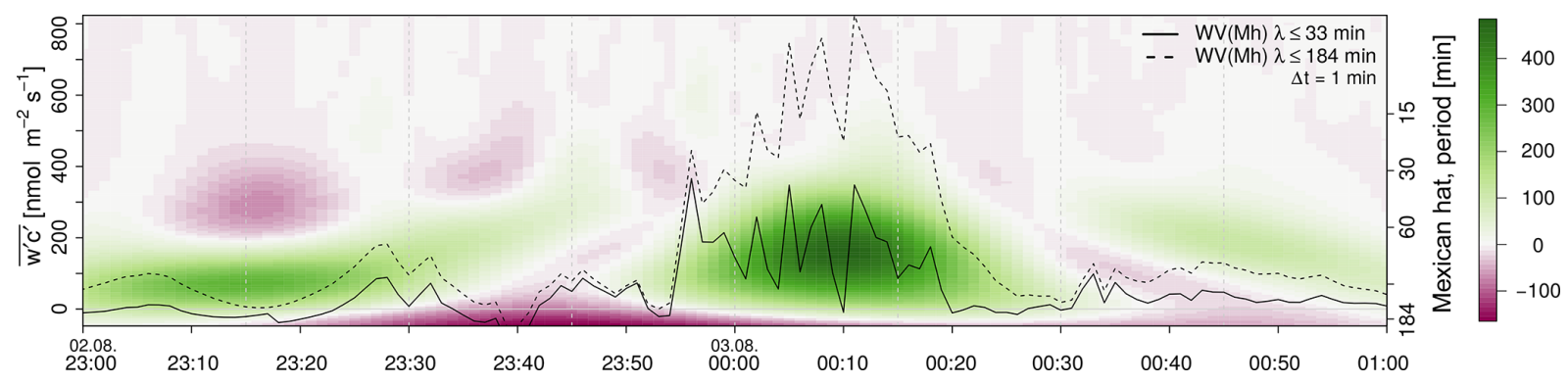

Figure 5. Mexican hat wavelet cross-scalogram for the case study event on 2-3 August 2014 at tower 1. The right axis numbers the period, while plotted lines refer to the left axis. Solid lines show the flux for an integration over all periods from $\lambda=2 \cdot \delta t$ to $\lambda=33$ min (Mh: Mexican hat), while the dashed line gives the flux up to $\lambda=184 \mathrm{~min}$. The colours in the wavelet cross-scalograms between $w$ and $c$ denote the flux intensity, where intensive colours indicate higher flux contributions downwards (negative, dark red) or upwards (positive, green).

intensity $\left(u_{*}<0.3 \mathrm{~m} \mathrm{~s}^{-1}\right)$, associated with a vertical temperature inversion and very low horizontal wind speeds. These conditions were interrupted at 03:10 MAGT, when the wind speeds first rapidly increased to $2.5 \mathrm{~m} \mathrm{~s}^{-1}$, only to drop to the previous low level $\left(\sim 0.5 \mathrm{~m} \mathrm{~s}^{-1}\right)$ immediately afterwards. This step change was followed by both $\mathrm{CH}_{4}$ concentration and vertical wind speed, where the former showed a sharp increase within seconds from around 2500 up to $5067 \mathrm{ppb}$ (tower 1). For this situation, the Morlet cross-wavelet spectrum showed a period of around 5 to 10 min that contributed most to the observed flux. This information, together with the characteristics of the high-frequency data, are indications that this particular event may have been triggered by an atmospheric gravity wave reaching the ground (Nappo, 2013; Serafimovich et al., 2017); however, lacking soundings of the vertical structure of the atmospheric boundary layer, this assumption remains speculative. 


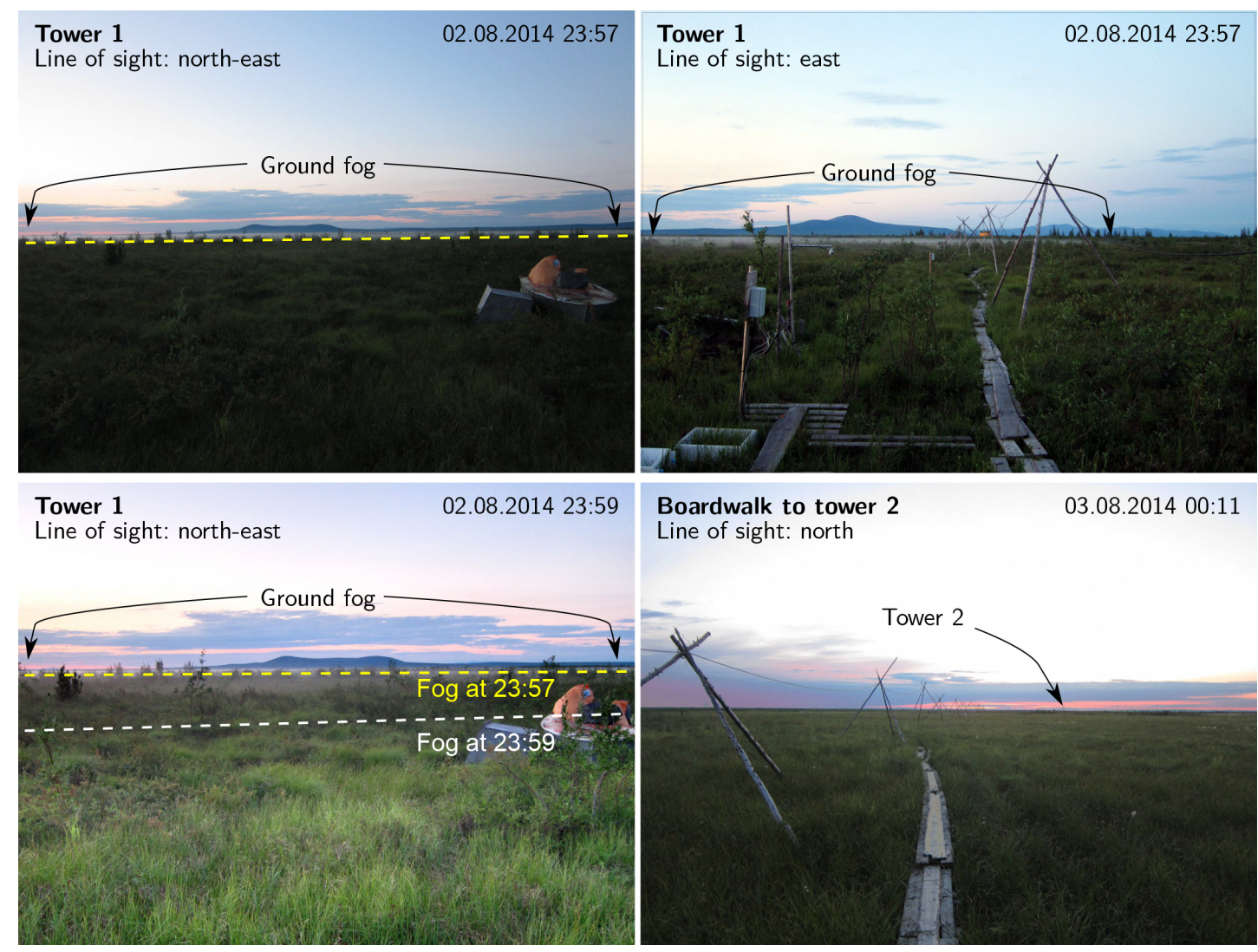

Figure 6. Photos of the study site directly at tower 1 (top and bottom left) and on the boardwalk between the power station at Ambolyka river and tower 2, taken between 2 August 2014 at 23:57 MAGT and 3 August 2014 at 00:11 MAGT.

Table 2. Night-time frequency (21:00-09:00 MAGT) of the wind directions over the whole measuring period for both towers in percent. The last row gives the frequency of wind directions observed for night-time peak events. Percentages greater than $20 \%$ are denoted in italics.

\begin{tabular}{lrrrrrrrr}
\hline Wind sector & $\mathrm{N}$ & $\mathrm{NE}$ & $\mathrm{E}$ & $\mathrm{SE}$ & $\mathrm{S}$ & $\mathrm{SW}$ & $\mathrm{W}$ & $\mathrm{NW}$ \\
\hline Tower 1 & 25.3 & 8.1 & 8.1 & 29.2 & 8.7 & 3.6 & 4.5 & 12.4 \\
Tower 2 & 25.2 & 8.3 & 7.2 & 28.2 & 8.7 & 4.1 & 4.8 & 13.6 \\
During events & 13.3 & 20.0 & 30.0 & 3.3 & 0.0 & 10.0 & 6.7 & 16.7 \\
\hline
\end{tabular}

\subsubsection{Low-level jets}

Low-level jets appeared to be the triggering mechanism for two pairs of events with distinctive characteristics. In one example, on 31 July 2014 , very low wind speeds $\left(\sim 0.5 \mathrm{~m} \mathrm{~s}^{-1}\right)$ from NW to $\mathrm{N}$ resulted in a stably stratified lower atmosphere and a strong temperature inversion. In the period before the event occurred, the longwave net radiation decreased from about 30 to $<15 \mathrm{~W} \mathrm{~m}^{-2}$, which could indicate that low stratus clouds were moving in. The onset of the event itself was marked by a rapid increase in the wind speed and a shift in wind direction by at least $45^{\circ}$ to $\mathrm{S}$ to $\mathrm{SW}$, which led to a sharp rise in $\mathrm{CH}_{4}$ concentration with maximum values around $4120 \mathrm{ppb}$ (tower 1). The flux rate also substantially increased for $5 \mathrm{~min}$. Within the next half-hour, the wind speed gradually decreased, then the wind switched back to the direction before the event. Under nocturnal stable stratification with a typically shallow stable boundary layer, the observed sudden increase in wind speed in combination with a change in wind direction are indicators for a significant vertical wind shear associated with a low-level jet, which was found to be connected with a significant increase in gas fluxes (Karipot et al., 2008; Foken et al., 2012c). But, as already mentioned for gravity waves, additional boundary layer measurements would be necessary to validate this assumption.

\subsubsection{Onset of turbulent flow}

The three remaining event pairs were detected under stable or neutral conditions and characterised by a gradually increasing, non-fluctuating wind speed, but no change in flux rates 


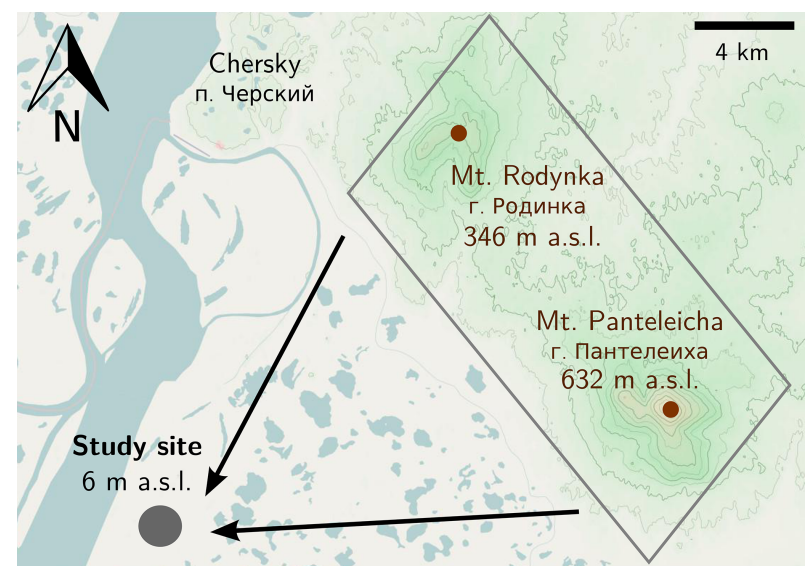

Figure 7. Flow path span of potential cold-air drains from the ridge between Mount Rodynka and Panteleicha through the flat floodplains of Kolyma river to the study site (map modified from http://www.openstreetmap.org, last access: 24 June 2015, copyright by OpenStreetMap contributors under Creative Commons License CC-BY-SA).

just before the event occurred. One example from 11 July demonstrated that only when the increase in winds finally started to yield fluctuations in wind speed did the event occur and the $\mathrm{CH}_{4}$ concentration increased by about $500 \mathrm{ppb}$ within $15 \mathrm{~min}$. After the event peak was reached, the concentration decreased quickly, while the wind speed fluctuations did not change. These patterns indicate that, before the event, vertical decoupling of the shallow boundary layer resulted in a laminar wind flow at sensor height, which explains the dampened fluctuations in wind speed. With the shift from laminar to turbulent flow, the previously accumulated $\mathrm{CH}_{4}$ near the ground could be transported up the sensor height, resulting in the observed flux peak. This observed change from laminar to turbulent flow is very similar to the conditions associated with a low-level jet, but due to the missing shift in wind directions we decided to separate both triggering mechanisms herein.

\section{Discussion}

\subsection{Advective contributions to flux events}

The EC method is based on the assumption that observations of turbulent fluctuations at a single point in space within the atmospheric surface layer can be used to obtain a representative flux rate from the ecosystem surrounding the flux tower. It is therefore of crucial importance for the interpretation of the impact of events for calculation of the local flux budgets whether the emitted $\mathrm{CH}_{4}$ was produced locally and just temporarily pooled near the surface, or horizontally advected towards the measurement location. Advective transport would bias the local mass balance of $\mathrm{CH}_{4}$ and any other atmospheric constituent to be monitored, therefore seriously undermining the theoretic assumptions that the EC technique relies on (Aubinet, 2008). If the fluxes detected by the instruments do not originate from the target area if advection is present, they should not be considered in the local flux budget. Accordingly, the detection of advection as a triggering mechanism behind an event deserves special attention, since inclusion of such data in the flux budget would lead to a systematic overestimation of fluxes from the local ecosystem.

To differentiate between events with and without advective flux contributions, the extension of the wavelet integration period provides essential information. For all methods compared herein, peak events are characterised by an intensive high-frequency turbulent component within an integration interval of up to $30 \mathrm{~min}$, which explains the increase in the flux. In addition to this, events that were influenced by advection also showed significant flux contributions from longer integration periods. This finding indicates that the elevated flux rates were not exclusively driven by turbulence and the venting of local $\mathrm{CH}_{4}$ pools near the ground, but also contained contributions from mesoscale motions spanning periods of minutes to hours.

The correlation in temporal trends of turbulence intensity and $\mathrm{CH}_{4}$ mixing ratios after the event can also be taken as an indicator for the source of the $\mathrm{CH}_{4}$. If the excess $\mathrm{CH}_{4}$ that created a peak flux during a detected event was coming from a limited source, i.e. local emissions that had been pooled in air layers close to the ground, the increased $\mathrm{CH}_{4}$ concentrations usually dropped to lower levels after only a few minutes. In this case, elevated flux rates also lasted for only a few minutes, while the increased turbulent mixing that initiated an event often persisted for a long time thereafter. In contrast, if the triggering mechanism had been advective transport, both $\mathrm{CH}_{4}$ concentrations and turbulence intensity should remain high for an extended period of time. Here, the reservoir that feeds the peak $\mathrm{CH}_{4}$ fluxes is substantially larger, since it is originating from a different region and is transported to the tower by katabatic winds. However, the differentiation is not as clean as that based on the wavelet integration periods, since the maximum amount of $\mathrm{CH}_{4}$ that can be vented from a local source close to the surface in the absence of advective contributions depends on many factors. Most importantly, the time since decoupling and the time since the last event took place influences how much $\mathrm{CH}_{4}$ can have re-accumulated, but the current $\mathrm{CH}_{4}$ emission rate from the ground and the intensity of the vertical mixing with the onset of the event also play a role in how long it will take until a local source will be depleted. To summarise, based on the length of an event alone a clean distinction between events with and without advective flux contributions cannot be performed. 


\subsubsection{Implications for designing an optimum observation strategy}

Statistics for the Chersky site show that, on average for the observation period in summer 2014, an event occurred about every other day ( 0.46 events per day). With the longer cluster events lasting for up to several hours, the average time covered by an event per day is $36.4 \mathrm{~min}$ at tower 1 , and $27.5 \mathrm{~min}$ at tower 2. Assuming that such events lead, at best, to lowerquality rating of the EC fluxes, and in the worst case constitute systematic biases to flux budgets determined through the EC technique, their net impact on longer-term flux budgets may be substantial, which should be investigated in a subsequent study. Our results demonstrate two major pathways through which events can systematically disturb the flux budget determined through the conventional EC approach, outlined in the following two paragraphs.

In the absence of advection, an event such as, for example a peak event that produces a short but intense outburst of $\mathrm{CH}_{4}$ with a duration of (significantly) less than the common integration interval for EC (30 min) constitutes a substantial violation of the steady-state assumption. As a consequence, the Reynolds decomposition that separates the high-frequency signal into a mean and turbulent component may produce incorrect positive and negative fluctuations of both vertical wind and trace gas concentrations. Depending on the nature of the event, the observation may in part be discarded as a spike, or the entire $30 \mathrm{~min}$ interval may be flagged as very low quality data and in turn be sorted out during data analysis, to be replaced by gap-filled values. In both cases, provided that the event was not caused by advection, the highemission event would disappear from the long-term $\mathrm{CH}_{4}$ flux budget, effectively leading to a systematic underestimation of net emissions. As a second potential scenario, the incorrect Reynolds decomposition may lead to both positive and negative flux biases, again dependent on the nature of the event, while a medium-quality flag will lead to the inclusion of this flux in long-term budget computation. In summary, the presence of events will introduce additional uncertainty into long-term flux observations, and in the case of $\mathrm{CH}_{4}$ is likely to lead to a systematic underestimation of flux budgets since peak events are likely to be sorted out by the processing software.

As a second major pathway to disturb EC flux budgets, events hold the potential to bias the local mass balance through advective flux contributions. Our statistics demonstrate that cold-air drainage is the responsible trigger for about half of the peak events detected by our algorithm at the Chersky observation site. Wind statistics and regional topography structure support the assumption that these events are associated with horizontal advection of $\mathrm{CH}_{4}$ that contributes a significant portion of the excess flux. Based on overall event statistics, this means that the site experiences on average about $2-3$ events per month with potential advective flux contributions during the growing season. For sev- eral reasons, the potential bias of this effect on the EC flux budget cannot be quantified yet. First, the total flux during an event triggered by cold-air drainage will be a composition of local $\mathrm{CH}_{4}$ emissions pooled near the surface and advected $\mathrm{CH}_{4}$. Second, a portion of the affected events will be sorted out by the EC quality flagging procedure, and (in this case rightfully) removed from the long-term budget computation. Therefore, as for the violation of steady-state conditions, advective events need to be considered as a potential cause for systematic biases, in this case overestimation, of EC flux budgets.

To facilitate a differentiation between these pathways, it would be important to validate these mesoscale triggering mechanisms in future field experiments. Influences by lowlevel jets or gravity waves could be verified by additional measurements of the atmospheric boundary layer, e.g. using a well established technique like SODAR/RASS (SOnic Detection And Ranging/Radio Acoustic Sounding System). The conceptual model of katabatic winds from the hill ridge located north-north-east of the study site could be investigated by installing additional nocturnal temperature measurements at heights of 20 to $50 \mathrm{~cm}$ in the hills and optionally also between the site and the hills. In order to visualise the events and to achieve a better understanding of how the accumulated $\mathrm{CH}_{4}$ is mixed up to the sensor during an event, it could be helpful to use the high-resolution fibre-optic temperature sensing approach, which was newly developed by Thomas et al. (2012) and has already been established for studies on cold-air layers in the nocturnal stable boundary layer (Zeeman et al., 2015). Additional vertical and horizontal $\mathrm{CH}_{4}$ concentration profiles could also be useful to visualise the flushing process of previously stored $\mathrm{CH}_{4}$ below the $\mathrm{EC}$ measuring level.

\subsubsection{Role of cluster events}

The potential role of events classified as "clusters" (coherent pattern, but no uniform shape) on potential systematic biases in flux budgets was excluded from this study. Clustered events, which made up the vast majority of event minutes detected by our algorithm, hold the potential to yield very different results between EC and wavelet methods; however, a uniform classification of for example environmental conditions and flux patterns was not conducted here, because this study focused on events that occur at short timescales, i.e. last only for minutes or some tens of minutes. Therefore a detailed investigation needs to be carried out as a followup field study including additional boundary layer measurements that will be exclusively dedicated to this phenomenon. It is very likely that these clusters were a result of recurring events, and complex recirculation of air masses enriched in trace gases. 


\section{Conclusions}

We showed that wavelet analysis can serve as a suitable method to resolve events of the order of minutes, which typically occurred at night and were not caused by ebullition or other local processes in the soil, but by different mesoscale meteorological phenomena. The signs of those phenomena were always visible at both towers (distance: $600 \mathrm{~m}$ ) simultaneously. The EC method failed to resolve the events correctly, because the steady-state assumption was not fulfilled, but it can be assumed that during regular EC processing these times usually would be filtered out and gap filled.

In detail, this study demonstrates that events which represent a violation of the basic assumption for the application of the EC technique are a regularly occurring phenomenon at the observation site Chersky in north-eastern Siberia. The exact localisation of these events in time as well as measurement of their duration and magnitude was made possible using wavelet analysis.

All events evaluated in this study started with a similar general setting: $\mathrm{CH}_{4}$, as emitted from the soil, accumulated near the ground because the surface layer was decoupled from the overlaying air during time periods of low turbulence. The break-up of these conditions was triggered by different mechanisms on the mesoscale. These mechanisms included the passage of fronts, atmospheric gravity waves, lowlevel jets, and katabatic winds. All events were characterised by sudden peaks in $\mathrm{CH}_{4}$ mixing ratios, often connected with increased horizontal wind speeds. This led to turbulent mixing and thus to short-term events with increased $\mathrm{CH}_{4}$ fluxes. It is very unlikely that the observed peaks were the result of sudden, simultaneous $\mathrm{CH}_{4}$ releases from the soil.

We found a strong positive correlation of short-term extreme $\mathrm{CH}_{4}$ flux events during the season with high soil temperatures and high median $\mathrm{CH}_{4}$ rates. This conjunction was likely formed by an increased $\mathrm{CH}_{4}$ production during times of high soil temperatures, which facilitated the accumulation of substantial $\mathrm{CH}_{4}$ pools when the surface layer was decoupled from the air above. Further, we found that events that were triggered by katabatic winds advected further $\mathrm{CH}_{4}$ to the site, which must have been emitted at a remote place within the flow path of the advection. As half of all events within our dataset were linked to advection, the peaks therefore do not necessarily represent the characteristics of the local $\mathrm{CH}_{4}$ production. This leads us to conclude that the respective flux events do not necessarily reflect the conditions at the site or within the EC flux footprint.

The portability of these results to other flux observation sites, within the Arctic and beyond, depends largely on prevalent local and regional atmospheric transport and mixing conditions. Particularly at sites where low winds at nighttime frequently enable an efficient decoupling of the surface layer, it is likely that similar phenomena may occur. As this study focused on the characterisation of single non-stationary events, the net impact of such events on the long-term $\mathrm{CH}_{4}$ budget as well as a comparison with typical EC gap-filling approaches still needs to be quantified, particularly since a large fraction of events were present in the form of clusters that proved difficult to classify and analyse. Such an analysis will be the subject of a follow-up study that is currently in progress.

Data availability. The dataset containing all necessary data to calculate methane fluxes for the case study of Sect. 3.4 is publicly available at https://doi.org/10.1594/PANGAEA.873260 (Schaller et al., 2017a). The data of the other examples are available upon request from Mathias Göckede.

Author contributions. All authors conceived and designed the research. CS prepared and performed the wavelet flux calculation as well as the data analysis and wrote the majority of the text. FK prepared and calculated the eddy covariance flux. MG, FK, and TF revised the initial manuscript. All of the authors discussed the results and contributed to the final research article. MG and TF supervised the study.

Competing interests. The author declares that there is no conflict of interest.

Acknowledgements. This work has been supported by the European Commission (PAGE21 project, FP7-ENV-2011, grant agreement no. 282700, and PerCCOM project, FP7-PEOPLE-2012-CIG, grant agreement no. PCIG12-GA-2012-333796), the German Ministry of Education and Research (CarboPerm-Project, BMBF grant no. 03G0836G), and the AXA Research Fund (PDOC_2012_W2 campaign, ARF fellowship Mathias Göckede). Furthermore the German Academic Exchange Service (DAAD) provided financial support for the travel expenses. Additionally we thank Andrew Durso for text editing of an earlier version of the paper.

The article processing charges for this open-access publication were covered by the Max Planck Society.

Review statement. This paper was edited by Laurens Ganzeveld and reviewed by Norbert Pirk and one anonymous referee.

\section{References}

Aubinet, M.: Eddy covariance $\mathrm{CO}_{2}$ flux measurements in nocturnal conditions: An analysis of the problem, Ecol. Appl., 18, 13681378, https://doi.org/10.1890/06-1336.1, 2008.

Aubinet, M., Vesala, T., and Papale, D. (Eds.): Eddy Covariance, A Practical Guide to Measurement and Data Analysis, Springer, Dordrecht, the Netherlands, 438 pp., 2012.

Bastviken, D., Tranvik, L. J., Downing, J. A., Crill, P. M., and Enrich-Prast, A.: Freshwater Methane Emissions Off- 
set the Continental Carbon Sink, Science, 331, p. 50, https://doi.org/10.1126/science.1196808, 2011.

Berchet, A., Bousquet, P., Pison, I., Locatelli, R., Chevallier, F., Paris, J.-D., Dlugokencky, E. J., Laurila, T., Hatakka, J., Viisanen, Y., Worthy, D. E. J., Nisbet, E., Fisher, R., France, J., Lowry, D., Ivakhov, V., and Hermansen, O.: Atmospheric constraints on the methane emissions from the East Siberian Shelf, Atmos. Chem. Phys., 16, 4147-4157, https://doi.org/10.5194/acp16-4147-2016, 2016.

Ciais, P., Sabine, C., Bala, G., Bopp, L., Brovkin, V., Canadell, J., Chhabra, A., DeFries, R., Galloway, J., Heimann, M., Jones, C., Le Quéré, C., Myneni, R., Piao, S., and Thornton, P.: Carbon and Other Biogeochemical Cycles, in: Climate Change 2013: The Physical Science Basis. Contribution of Working Group I to the Fifth Assessment Report of the Intergovernmental Panel on Climate Change, edited by: Stocker, T., Qin, D., Plattner, G.K., Tignor, M., Allen, S., Boschung, J., Nauels, A., Xia, Y., Bex, V., and Midgley, P., Cambridge University Press, Cambridge and New York, 465-570, 2013.

Collineau, S. and Brunet, Y.: Detection of turbulent coherent motions in a forest canopy part I: Wavelet analysis, Bound.-Lay. Meteorol., 65, 357-379, https://doi.org/10.1007/BF00707033, 1993a.

Collineau, S. and Brunet, Y.: Detection of turbulent coherent motions in a forest canopy part II: Time-scales and conditional averages, Bound.-Lay. Meteorol., 66, 49-73, https://doi.org/10.1007/BF00705459, 1993b.

Cooper, M. D. A., Estop-Aragonés, C., Fisher, J. P., Thierry, A., Garnett, M. H., Charman, D. J., Murton, J. B., Phoenix, G. K., Treharne, R., Kokelj, S. V., Wolfe, S. A., Lewkowicz, A. G., Williams, M., and Hartley, I. P.: Limited contribution of permafrost carbon to methane release from thawing peatlands, Nat. Clim. Change, 7, 507-511, https://doi.org/10.1038/nclimate3328, 2017.

Corradi, C., Kolle, O., Walter, K., Zimov, S. A., and Schulze, E. D.: Carbon dioxide and methane exchange of a north-east Siberian tussock tundra, Glob. Change Biol., 11, 1910-1925, https://doi.org/10.1111/j.1365-2486.2005.01023.x, 2005.

Desjardins, R. L., Macpherson, J. I., Schuepp, P. H., and Karanja, F.: An Evaluation of Aircraft Flux Measurements of $\mathrm{CO}_{2}$, WaterVapor and Sensible Heat, Bound.-Lay. Meteorol., 47, 55-69, https://doi.org/10.1007/BF00122322, 1989.

Emmerton, C. A., St. Louis, V. L., Lehnherr, I., Humphreys, E. R., Rydz, E., and Kosolofski, H. R.: The net exchange of methane with high Arctic landscapes during the summer growing season, Biogeosciences, 11, 3095-3106, https://doi.org/10.5194/bg-113095-2014, 2014.

Fisher, J. P., Estop-Aragonés, C., Thierry, A., Charman, D. J., Wolfe, S. A., Hartley, I. P., Murton, J. B., Williams, M., and Phoenix, G. K.: The influence of vegetation and soil characteristics on active-layer thickness of permafrost soils in boreal forest, Glob. Change Biol., 22, 3127-3140, https://doi.org/10.1111/gcb.13248, 2016.

Foken, T. and Wichura, B.: Tools for quality assessment of surfacebased flux measurements, Agr. Forest Meteorol., 78, 83-105, https://doi.org/10.1016/0168-1923(95)02248-1, 1996.

Foken, T., Dlugi, R., and Kramm, G.: On the determination of dry deposition and emission of gaseous compounds at the biosphereatmosphere interface, Meteorol. Z., 4, 91-118, 1995.
Foken, T., Göckede, M., Mauder, M., Mahrt, L., Amiro, B., and Munger, W.: Post-Field Data Quality Control, in: Handbook of Micrometeorology, edited by: Lee, X., Massman, W., and Law, B., Kluwer, Dordrecht, 181-208, 2004.

Foken, T., Aubinet, M., and Leuning, R.: The eddy covariance method, in: Eddy covariance: a practical guide to measurement and data analysis, edited by: Aubinet, M., Vesala, T., and Papale, D., Springer Atmospheric Sciences, Springer, Dordrecht, 1-19, 2012a.

Foken, T., Leuning, R., Oncley, S., Mauder, M., and Aubinet, M.: Corrections and Data Quality Control, in: Eddy covariance: a practical guide to measurement and data analysis, edited by: Aubinet, M., Vesala, T., and Papale, D., Springer Atmospheric Sciences, Springer, Dordrecht, 85-131, https://doi.org/10.1007/978-94-007-2351-1_1, 2012b.

Foken, T., Meixner, F. X., Falge, E., Zetzsch, C., Serafimovich, A., Bargsten, A., Behrendt, T., Biermann, T., Breuninger, C., Dix, S., Gerken, T., Hunner, M., Lehmann-Pape, L., Hens, K., Jocher, G., Kesselmeier, J., Lüers, J., Mayer, J.-C., Moravek, A., Plake, D., Riederer, M., Rütz, F., Scheibe, M., Siebicke, L., Sörgel, M., Staudt, K., Trebs, I., Tsokankunku, A., Welling, M., Wolff, V., and Zhu, Z.: Coupling processes and exchange of energy and reactive and non-reactive trace gases at a forest site - results of the EGER experiment, Atmos. Chem. Phys., 12, 1923-1950, https://doi.org/10.5194/acp-12-1923-2012, 2012.

Fratini, G. and Mauder, M.: Towards a consistent eddy-covariance processing: an intercomparison of EddyPro and TK3, Atmos. Meas. Tech., 7, 2273-2281, https://doi.org/10.5194/amt-7-22732014, 2014.

Glaser, P. H., Chanton, J. P., Morin, P., Rosenberry, D. O., Siegel, D. I., Ruud, O., Chasar, L. I., and Reeve, A. S.: Surface deformations as indicators of deep ebullition fluxes in a large northern peatland, Global Biogeochem. Cy., 18, GB1003, https://doi.org/10.1029/2003GB002069, 2004.

Göckede, M., Kittler, F., Kwon, M. J., Burjack, I., Heimann, M., Kolle, O., Zimov, N., and Zimov, S.: Shifted energy fluxes, increased Bowen ratios, and reduced thaw depths linked with drainage-induced changes in permafrost ecosystem structure, The Cryosphere, 11, 2975-2996, https://doi.org/10.5194/tc-112975-2017, 2017.

Goodrich, J. P., Oechel, W. C., Gioli, B., Moreaux, V., Murphy, P. C., Burba, G., and Zona, D.: Impact of different eddy covariance sensors, site set-up, and maintenance on the annual balance of $\mathrm{CO}_{2}$ and $\mathrm{CH}_{4}$ in the harsh Arctic environment, Agr. Forest Meteorol., 228-229, 239-251, https://doi.org/10.1016/j.agrformet.2016.07.008, 2016.

Hartmann, D. L., Klein Tank, A. M. G., Rusticucci, M., Alexander, R. V., Brönnimann, S., Charabi, Y., Dentener, F. J., Dlugokencky, E. J., Easterling, D. R., Kaplan, A., Soden, B. J., Thorne, P. W., Wild, M., and Zhai, P. M.: Observations: Atmosphere and Surface, in: Climate Change 2013: The Physical Science Basis. Contribution of Working Group I to the Fifth Assessment Report of the Intergovernmental Panel on Climate Change, edited by: Stocker, T., Qin, D., Plattner, G.-K., Tignor, M., Allen, S., Boschung, J., Nauels, A., Xia, Y., Bex, V., and Midgley, P., Cambridge University Press, Cambridge and New York, 159-254, 2013. 
Hoaglin, D. C., Mosteller, F., and Tukey, J. W.: Understanding robust and exploratory data analysis, John Wiley \& Sons, New York, 2000.

Hoffmann, M., Schulz-Hanke, M., Garcia Alba, J., Jurisch, N., Hagemann, U., Sachs, T., Sommer, M., and Augustin, J.: A simple calculation algorithm to separate highresolution $\mathrm{CH}_{4}$ flux measurements into ebullition- and diffusionderived components, Atmos. Meas. Tech., 10, 109-118, https://doi.org/10.5194/amt-10-109-2017, 2017.

Iwata, H., Hirata, R., Takahashi, Y., Miyabara, Y., Itoh, M., and Iizuka, K.: Partitioning Eddy-Covariance Methane Fluxes from a Shallow Lake into Diffusive and Ebullitive Fluxes, Bound.Lay. Meteorol., 169, 413-428, https://doi.org/10.1007/s10546018-0383-1, 2018.

Kaiser, S., Göckede, M., Castro-Morales, K., Knoblauch, C., Ekici, A., Kleinen, T., Zubrzycki, S., Sachs, T., Wille, C., and Beer, C.: Process-based modelling of the methane balance in periglacial landscapes (JSBACH-methane), Geosci. Model Dev., 10, 333358, https://doi.org/10.5194/gmd-10-333-2017, 2017.

Karipot, A., Leclerc, M. Y., Zhang, G., Lewin, K. F., Nagy, J., Hendrey, G. R., and Starr, G.: Influence of nocturnal low-level jet on turbulence structure and $\mathrm{CO}_{2}$ flux measurements over a forest canopy, J. Geophys. Res., 113, D10102, https://doi.org/10.1029/2007jd009149, 2008.

Katul, G. G. and Parlange, M. B.: Analysis of land-surface heat fluxes using the orthonormal wavelet approach, Water Resour. Res., 31, 2743-2749, https://doi.org/10.1029/95WR00003, 1995.

Kittler, F., Burjack, I., Corradi, C. A. R., Heimann, M., Kolle, O., Merbold, L., Zimov, N., Zimov, S., and Göckede, M.: Impacts of a decadal drainage disturbance on surface-atmosphere fluxes of carbon dioxide in a permafrost ecosystem, Biogeosciences, 13, 5315-5332, https://doi.org/10.5194/bg-13-5315-2016, 2016.

Kittler, F., Eugster, W., Foken, T., Heimann, M., Kolle, O., and Göckede, M.: High-quality eddy-covariance $\mathrm{CO}_{2}$ budgets under cold climate conditions, J. Geophys. Res.-Biogeo., 122, 20642084, https://doi.org/10.1002/2017JG003830, 2017a.

Kittler, F., Heimann, M., Kolle, O., Zimov, N., Zimov, S., and Göckede, M.: Long-Term Drainage Reduces $\mathrm{CO}_{2}$ Uptake and $\mathrm{CH}_{4}$ Emissions in a Siberian Permafrost Ecosystem, Global Biogeochem. Cy., 31, 1704-1717, https://doi.org/10.1002/2017GB005774, 2017b.

Kolle, O. and Rebmann, C.: EddySoft - Documentation of a Software Package to Acquire and Process Eddy Covariance Data, Technical Report Nr. 10. Max-Planck-Institute for Biogeochemistry, Jena, 2007.

Kwon, M. J., Beulig, F., Ilie, I., Wildner, M., Küsel, K., Merbold, L., Mahecha, M. D., Zimov, N., Zimov, S. A., Heimann, M., Schuur, E. A. G., Kostka, J. E., Kolle, O., Hilke, I., and Göckede, M.: Plants, microorganisms, and soil temperatures contribute to a decrease in methane fluxes on a drained Arctic floodplain, Glob. Change Biol., 23, 2396-2412, https://doi.org/10.1111/gcb.13558, 2017.

Lee, X., Finnigan, J., and Paw U, K. T.: Coordinate systems and flux bias error, in: Handbook of Micrometeorology, edited by: Lee, X., Massman, W., and Law, B., Kluwer, Dordrecht, 33-66, 2004.

Masson-Delmotte, V., Schulz, M., Abe-Ouchi, A., Beer, J., Ganopolski, A., Gonzalez Rouco, J. F., Jansen, E., Lambeck, K.,
Luterbacher, J., Naish, T., Osborn, T., Otto-Bliesner, B., Quinn, T., Ramesh, R., Rojas, M., Shao, X., and Timmermann, A.: Information from Paleoclimate Archives, in: Climate Change 2013: The Physical Science Basis. Contribution of Working Group I to the Fifth Assessment Report of the Intergovernmental Panel on Climate Change, edited by: Stocker, T., Qin, D., Plattner, G.-K., Tignor, M., Allen, S., Boschung, J., Nauels, A., Xia, Y., Bex, V., and Midgley, P., Cambridge University Press, Cambridge and New York, 383-464, 2013.

Mauder, M. and Foken, T.: Documentation and Instruction Manual of the Eddy-Covariance Software Package TK3 (update), available at: https://epub.uni-bayreuth.de/342/ (last access: 1 February 2017), work Report, University of Bayreuth, Department of Micro-meteorology, 2015a.

Mauder, M. and Foken, T.: Eddy-Covariance software TK3, Zenodo, https://doi.org/10.5281/zenodo.20349, 2015 b.

Mauder, M., Foken, T., Clement, R., Elbers, J. A., Eugster, W., Grünwald, T., Heusinkveld, B., and Kolle, O.: Quality control of CarboEurope flux data - Part 2: Inter-comparison of eddy-covariance software, Biogeosciences, 5, 451-462, https://doi.org/10.5194/bg-5-451-2008, 2008.

Mauder, M., Cuntz, M., Drüe, C., Graf, A., Rebmann, C., Schmid, H. P., Schmidt, M., and Steinbrecher, R.: A strategy for quality and uncertainty assessment of long-term eddycovariance measurements, Agr. Forest Meteorol., 169, 122-135, https://doi.org/10.1016/j.agrformet.2012.09.006, 2013.

McEwing, K. R., Fisher, J. P., and Zona, D.: Environmental and vegetation controls on the spatial variability of $\mathrm{CH}_{4}$ emission from wet-sedge and tussock tundra ecosystems in the Arctic, Plant Soil, 388, 37-52, https://doi.org/10.1007/s11104-0142377-1, 2015.

Merbold, L., Kutsch, W. L., Corradi, C., Kolle, O., Rebmann, C., Stoy, P. C., Zimov, S. A., and Schulze, E.-D.: Artificial drainage and associated carbon fluxes $\left(\mathrm{CO}_{2} / \mathrm{CH}_{4}\right)$ in a tundra ecosystem, Glob. Change Biol., 15, 2599-2614, https://doi.org/10.1111/j.1365-2486.2009.01962.x, 2009.

Myhre, G., Shindell, D., Bréon, F.-M., Collins, W., Fuglestvedt, J., Huang, J., Koch, D., Lamarque, J.-F., Lee, D., Mendoza, B., Nakajima, T., Robock, A., Stephens, G., Takemura, T., and Zhang, H.: Anthropogenic and Natural Radiative Forcing, in: Climate Change 2013: The Physical Science Basis. Contribution of Working Group I to the Fifth Assessment Report of the Intergovernmental Panel on Climate Change, edited by: Stocker, T., Qin, D., Plattner, G.-K., Tignor, M., Allen, S., Boschung, J., Nauels, A., Xia, Y., Bex, V., and Midgley, P., Cambridge University Press, Cambridge and New York, 659-740, 2013.

Nappo, C. J.: An introduction to atmospheric gravity waves, Academic Press, Amsterdam, 2nd Edn., 2013.

Nisbet, E. G., Dlugokencky, E. J., Manning, M., Lowry, D., and Fisher, R. E.: Rising atmospheric methane: 2007-2014 growth and isotopic shift, Global Biogeochem. Cy., 30, 1356-1370, https://doi.org/10.1002/2016GB005406, 2016.

Oncley, S. P., Businger, J. A., Itsweire, E. C., Friehe, C. A., Larue, J. C., and Chang, S. S.: Surface layer profiles and turbulence measurements over uniform land under near-neutral conditions, in: 9th Symp on Boundary Layer and Turbulence, Amer. Meteor. Soc., Roskilde, Denmark, 237-240, 1990.

Papale, D., Reichstein, M., Aubinet, M., Canfora, E., Bernhofer, C., Kutsch, W., Longdoz, B., Rambal, S., Valentini, R., Vesala, T., 
and Yakir, D.: Towards a standardized processing of Net Ecosystem Exchange measured with eddy covariance technique: algorithms and uncertainty estimation, Biogeosciences, 3, 571-583, https://doi.org/10.5194/bg-3-571-2006, 2006.

Parazoo, N. C., Commane, R., Wofsy, S. C., Koven, C. D., Sweeney, C., Lawrence, D. M., Lindaas, J., Chang, R. Y. W., and Miller, C. E.: Detecting regional patterns of changing $\mathrm{CO}_{2}$ flux in Alaska, P. Natl. Acad. Sci. USA, 113, 7733-7738, https://doi.org/10.1073/pnas.1601085113, 2016.

Peltola, O., Raivonen, M., Li, X., and Vesala, T.: Technical note: Comparison of methane ebullition modelling approaches used in terrestrial wetland models, Biogeosciences, 15, 937-951, https://doi.org/10.5194/bg-15-937-2018, 2018.

Percival, D. and Walden, A. T.: Wavelet methods for time series analysis, Cambridge Univ. Press, Cambridge, 2000.

Raivonen, M., Smolander, S., Backman, L., Susiluoto, J., Aalto, T., Markkanen, T., Mäkelä, J., Rinne, J., Peltola, O., Aurela, M., Lohila, A., Tomasic, M., Li, X., Larmola, T., Juutinen, S., Tuittila, E.-S., Heimann, M., Sevanto, S., Kleinen, T., Brovkin, V., and Vesala, T.: HIMMELI v1.0: HelsinkI Model of MEthane buiLdup and emIssion for peatlands, Geosci. Model Dev., 10, 46654691, https://doi.org/10.5194/gmd-10-4665-2017, 2017.

Rebmann, C., Kolle, O., Heinesch, B., Queck, R., Ibrom, A., and Aubinet, M.: Data Acquisition and Flux Calculations, in: Eddy covariance: a practical guide to measurement and data analysis, edited by: Aubinet, M., Vesala, T., and Papale, D., Springer Atmospheric Sciences, Springer, Dordrecht, 59-84, 2012.

Sachs, T., Giebels, M., Boike, J., and Kutzbach, L.: Environmental controls on $\mathrm{CH}_{4}$ emission from polygonal tundra on the microsite scale in the Lena river delta, Siberia, Glob. Change Biol., 16, 3096-3110, https://doi.org/10.1111/j.13652486.2010.02232.x, 2010.

Saunois, M., Bousquet, P., Poulter, B., Peregon, A., Ciais, P., Canadell, J. G., Dlugokencky, E. J., Etiope, G., Bastviken, D., Houweling, S., Janssens-Maenhout, G., Tubiello, F. N., Castaldi, S., Jackson, R. B., Alexe, M., Arora, V. K., Beerling, D. J., Bergamaschi, P., Blake, D. R., Brailsford, G., Brovkin, V., Bruhwiler, L., Crevoisier, C., Crill, P., Covey, K., Curry, C., Frankenberg, C., Gedney, N., Höglund-Isaksson, L., Ishizawa, M., Ito, A., Joos, F., Kim, H.-S., Kleinen, T., Krummel, P., Lamarque, J.-F., Langenfelds, R., Locatelli, R., Machida, T., Maksyutov, S., McDonald, K. C., Marshall, J., Melton, J. R., Morino, I., Naik, V., O'Doherty, S., Parmentier, F.-J. W., Patra, P. K., Peng, C., Peng, S., Peters, G. P., Pison, I., Prigent, C., Prinn, R., Ramonet, M., Riley, W. J., Saito, M., Santini, M., Schroeder, R., Simpson, I. J., Spahni, R., Steele, P., Takizawa, A., Thornton, B. F., Tian, H., Tohjima, Y., Viovy, N., Voulgarakis, A., van Weele, M., van der Werf, G. R., Weiss, R., Wiedinmyer, C., Wilton, D. J., Wiltshire, A., Worthy, D., Wunch, D., Xu, X., Yoshida, Y., Zhang, B., Zhang, Z., and Zhu, Q.: The global methane budget 2000-2012, Earth Syst. Sci. Data, 8, 697-751, https://doi.org/10.5194/essd-8-697-2016, 2016a.

Saunois, M., Jackson, R. B., Bousquet, P., Poulter, B., and Canadell, J. G.: The growing role of methane in anthropogenic climate change, Environ. Res. Lett., 11, 120207, https://doi.org/10.1088/1748-9326/11/12/120207, 2016b.

Schaefer, H., Fletcher, S. E. M., Veidt, C., Lassey, K. R., Brailsford, G. W., Bromley, T. M., Dlugokencky, E. J., Michel, S. E., Miller, J. B., Levin, I., Lowe, D. C., Martin, R. J., Vaughn, B. H., and
White, J. W. C.: A 21st-century shift from fossil-fuel to biogenic methane emissions indicated by $\left(\mathrm{CH}_{4}\right)-\mathrm{C}-13$, Science, 352, 80 84, https://doi.org/10.1126/science.aad2705, 2016.

Schaller, C., Göckede, M., and Foken, T.: Flux calculation of short turbulent events in Chersky in the Sakha (Yakutia) Republic, Far Eastern Federal District of Russia, https://doi.org/10.1594/PANGAEA.873260, 2017a.

Schaller, C., Göckede, M., and Foken, T.: Flux calculation of short turbulent events - comparison of three methods, Atmos. Meas. Tech., 10, 869-880, https://doi.org/10.5194/amt-10-8692017, 2017b.

Schulz, A., Schaller, C., Maturilli, M., Boike, J., Ritter, C., and Foken, T.: Surface energy fluxes during the total solar eclipse over Ny-Alesund, Svalbard, on 20 March 2015, Meteorol. Z., 26, 431-440, https://doi.org/10.1127/metz/2017/0846, 2017.

Schwietzke, S., Sherwood, O. A., Bruhwiler, L. M. P., Miller, J. B., Etiope, G., Dlugokencky, E. J., Michel, S. E., Arling, V. A., Vaughn, B. H., White, J. W. C., and Tans, P. P.: Upward revision of global fossil fuel methane emissions based on isotope database, Nature, 538, 88-91, https://doi.org/10.1038/nature19797, 2016.

Serafimovich, A., Hübner, J., Leclerc, M. Y., Duarte, H. F., and Foken, T.: Influence of Low-Level Jets and Gravity Waves on Turbulent Fluxes, in: Energy and Matter Fluxes of a Spruce Forest Ecosystem, edited by: Foken, T., 229th Ecological Studies, 247276, Springer, Cham, 2017.

Shakhova, N., Semiletov, I., Leifer, I., Sergienko, V., Salyuk, A., Kosmach, D., Chernykh, D., Stubbs, C., Nicolsky, D., Tumskoy, V., and Gustafsson, Ö.: Ebullition and storm-induced methane release from the East Siberian Arctic Shelf, Nat. Geosci., 6, 1-7, https://doi.org/10.1038/ngeo2007, 2013.

Sweeney, C., Dlugokencky, E., Miller, C. E., Wofsy, S., Karion, A., Dinardo, S., Chang, R. Y.-W., Miller, J. B., Bruhwiler, L., Crotwell, A. M., Newberger, T., McKain, K., Stone, R. S., Wolter, S. E., Lang, P. E., and Tans, P.: No significant increase in long-term $\mathrm{CH}_{4}$ emissions on North Slope of Alaska despite significant increase in air temperature, Geophys. Res. Lett., 43, 6604-6611, https://doi.org/10.1002/2016GL069292, 2016.

Tan, Z. and Zhuang, Q.: Methane emissions from pan-Arctic lakes during the 21st century: An analysis with process-based models of lake evolution and biogeochemistry, J. Geophys. Res.-Biogeo., 120, 2641-2653, https://doi.org/10.1002/2015JG003184, 2015.

Terradellas, E., Morales, G., Cuxart, J., and Yagüe, C.: Wavelet methods: application to the study of the stable atmospheric boundary layer under non-stationary conditions, Dynam. Atmos. Oceans, 34, 225-244, https://doi.org/10.1016/S03770265(01)00069-0, 2001.

Thomas, C. K., Kennedy, A. M., Selker, J. S., Moretti, A., Schroth, M. H., Smoot, A. R., Tufillaro, N. B., and Zeeman, M. J.: High-Resolution Fibre-Optic Temperature Sensing: A New Tool to Study the Two-Dimensional Structure of Atmospheric Surface-Layer Flow, Bound.-Lay. Meteorol., 142, 177192, https://doi.org/10.1007/s10546-011-9672-7, 2012.

Torrence, C. and Compo, G. P.: A Practical Guide to Wavelet Analysis, B. Am. Meteorol. Soc., 79, 61-78, https://doi.org/10.1175/15200477(1998)079<0061:APGTWA>2.0.CO;2, 1998.

Trevino, G. and Andreas, E. L.: On wavelet analysis of nonstationary turbulence, Bound.-Lay. Meteorol., 81, 271-288, 1996. 
Wik, M., Crill, P. M., Varner, R. K., and Bastviken, D.: Multiyear measurements of ebullitive methane flux from three subarctic lakes, J. Geophys. Res.-Biogeo., 118, 1307-1321, https://doi.org/10.1002/jgrg.20103, 2013.

Zeeman, M. J., Selker, J. S., and Thomas, C. K.: Near-Surface Motion in the Nocturnal, Stable Boundary Layer Observed with Fibre-Optic Distributed Temperature Sensing, Bound.-Lay. Meteorol., 154, 189-205, https://doi.org/10.1007/s10546-014-99729, 2015

Zhang, Y., Sachs, T., Li, C., and Boike, J.: Upscaling methane fluxes from closed chambers to eddy covariance based on a permafrost biogeochemistry integrated model, Glob. Change Biol., 18, 1428-1440, https://doi.org/10.1111/j.1365-2486.2011.02587.x, 2012.
Zona, D., Gioli, B., Commane, R., Lindaas, J., Wofsy, S. C., Miller, C. E., Dinardo, S. J., Dengel, S., Sweeney, C., Karion, A., Chang, R. Y. W., Henderson, J. M., Murphy, P. C., Goodrich, J. P., Moreaux, V., Liljedahl, A., Watts, J. D., Kimball, J. S., Lipson, D. A., and Oechel, W. C.: Cold season emissions dominate the Arctic tundra methane budget., P. Natl. Acad. Sci. USA, 113, 40-45, https://doi.org/10.1073/pnas.1516017113, 2016. 